Article

\title{
Experimental and Numerical Investigation into Failure Modes of Tension Angle Members Connected by One Leg
}

\author{
Edyta Bernatowska *(D) and Lucjan Ślęczka \\ Faculty of Civil and Environmental Engineering and Architecture, Rzeszów University of Technology, \\ Poznańska 2, 35-084 Rzeszow, Poland; sleczka@prz.edu.pl \\ * Correspondence: e_bernat@prz.edu.pl
}

Citation: Bernatowska, E.; Ślęczka, L. Experimental and Numerical Investigation into Failure Modes of Tension Angle Members Connected by One Leg. Materials 2021, 14, 5141. https://doi.org/10.3390/ma14185141

Academic Editors: Patryk Rozylo, Hubert Debski and

Katarzyna Falkowicz

Received: 27 July 2021

Accepted: 3 September 2021

Published: 7 September 2021

Publisher's Note: MDPI stays neutral with regard to jurisdictional claims in published maps and institutional affiliations.

\begin{abstract}
This paper presents the results of experimental and numerical tests on angle members connected by one leg with a single row of bolts. This study was designed to determine which failure mode governs the resistance of such joints: net section rupture or block tearing rupture. Experimental tests were insufficient to completely identify the failure modes, and it was necessary to conduct numerical simulations. Finite element analysis of steel element resistance based on rupture required advanced material modelling, taking into account ductile initiation and propagation of fractures. This was realised using the Gurson-Tvergaard-Needleman porous material model, which allows for analysis of the joint across the full scope of its behaviour, from unloaded state to failure. Through experimental testing and numerical simulations, both failure mechanisms (net section and block tearing) were examined, and an approach to identify the failure mode was proposed. The obtained results provided experimental and numerical evidence to validate the strength function used in design standards. Finally, the obtained results of the load capacity were compared with the design procedures given in the Eurocode 3's current and 2021 proposed editions.
\end{abstract}

Keywords: steel angle members; lap bolted connection; numerical simulations; porous material model; shear lag effect

\section{Introduction}

Hot-rolled equal and unequal angles are some of the most common structural elements and are usually used as axially loaded tension or compression members. The resistance of these angles when loaded in axial tension strongly depends on the way they are connected. Owing to ease of manufacture and assembly, the most common form of joining is connecting one leg by a single or double row of bolts, while the other, outstanding leg remains unconnected. This results in weakening of the gross cross-section, formation of eccentricities, and the occurrence of a shear lag phenomenon defined as non-uniform tensile stress distribution in the vicinity of a connection, produced by applying local force on the joint.

Numerous experimental studies have been conducted to assess the load capacities of such connections. Munse and Chesson [1], Kulak and Wu [2], and Munter and Bouwman [3] conducted tension tests on a wide range of angles. The observed failure modes were described as bearing failure, shear failure of the bolts, and net section failure of the angle. Based on these tests, a few empirical equations were proposed to calculate the net section resistance of tensioned members. Such equations allow the treatment of angles connected by one leg as concentrically loaded without requiring time-consuming determination of bending effects and stress concentration and taking into account the influence of the reduced net cross-sectional area $\mathrm{A}_{\text {net }}$ on the bending and shear lag effect, as shown in Figure 1a. 


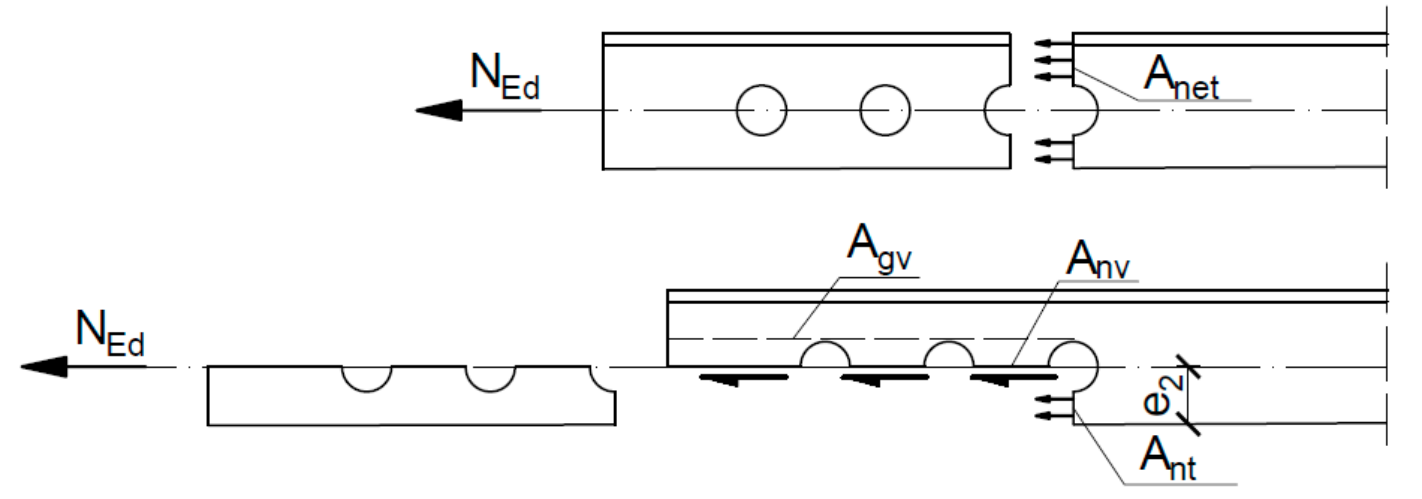

Figure 1. End of the angle weakened by bolt holes; (a) the net cross-section area $A_{\text {net }},(\mathbf{b})$ cross-section areas subjected to tension and shear.

Although block shear tearing was first identified in coped beams by Birkemoe and Gilmor [4] in the second half of the 20th century, it quickly became apparent that such failure modes can be decisive in angles connected by one leg. This form of failure occurs due to simultaneous shear failure at the row of bolts along the shear face of the hole group and tensile rupture along the line of bolt holes on the tension face of the bolt group, as shown in Figure 1b. A significant number of investigations have been performed to study the failure mode of angles connected by one leg. Orbison et al. [5] conducted an experimental test of steel angles and tees designed to produce block shear failure and demonstrated the influence of geometrical parameters on resistance. Additional test data were provided by Epstein [6], Ke et al. [7], Jiang et al. [8], and Dhanuskar and Gupta [9]. Some of the studies also covered block shear in angle connections with double-line bolt arrangements [6,9] and the block shear resistance of high-strength steel angle members [7,8]. The block shear resistance of angle connections is generally considered to be a small part of the block shear resistance problem of all bolted connections, and the applied design provisions against block shear failures are mainly calibrated on gusset plates, wide flange sections, tees or coped beam connections.

Today, numerical simulations are an efficient alternative or supplement to experimental tests. Epstein and Chamarajanagar [10] studied the influence of the outstanding leg, shear length, and staggered spacing of fasteners using an elastic-plastic material model. Kulak and $\mathrm{Wu}$ [2] made their test more complete by finite element (FE) analysis using nonlinear material and geometry effect behaviour. An extensive FE study on block shear failure of steel tension elements was conducted by Topkaya [11]. Over a thousand nonlinear analyses were performed to identify parameters that influence block shear capacity, but few were dedicated to eccentrically loaded elements, such as angles connected by one leg. Contemporary research work, apart from test results, also includes FE analyses carried out with increasing degrees of complexity [7-9]. The modern approach is to use material and geometric nonlinearities and replace simple strain-base criteria to determine the failure load of members using more advanced material damage criteria. In addition, contact conditions that provide proper load transfer to bolts are now usually included. Recently, sophisticated numerical studies of block shear have been carried out that included fracture initiation and propagation, but they were limited to rectangular gusset plate connections or coped beam connections $[12,13]$.

The research on the resistance of angles connected by one leg can be divided into two groups: one deals with the phenomenon of the ultimate resistance of the net cross section, whereas the other deals only with block shear tearing. There is a lack of studies that trace both of these mechanisms in one connection and investigate the boundaries between individual failure modes. Net cross-section failure and block shear tearing in design provisions are described by appropriate individual strength functions. Each function should be statistically evaluated based on test results in which the proper failure mode 
has occurred. Unfortunately, identification of the failure mode in many experimental tests is difficult or impossible, because both net section tearing and block tearing result in a rupture along the line between the bolt hole edge and angle edge $\left(\mathrm{e}_{2}\right.$ in the direction perpendicular to the acting load: see Figure 1). Numerical analyses may be helpful for solving this problem. Considering the advances in FE modelling, simulations on connections pertaining to the ultimate resistance of the net cross-section or block shear tearing should include the material failure process characterised by ductile fracture. Such sophisticated FE analyses have been performed for block shear fracture of gusset plates and coped beam connections [12,13] but are not yet available for angle connections.

The importance of tension angle members and their joints in different applications is underlined in the construction and maintenance of many metal structures such as masts, transmission line towers, transfer joints in the form of gusset plates [14], and also all-composite modular wall systems [15]. Such wall systems are mainly made of pultruded GFRP profiles, joined by means of metal connectors, often in the form of short angle members. Thus, in many cases metal angle connections significantly influence the behaviour of the whole structure and their sophisticated analysis is crucial for structure integrity.

In this paper, the results of an experimental study on the ultimate resistance of tension angle members connected by one leg using a single row of bolts are presented. They are utilised for validation of numerical modelling, taking into account yielding and ductile crack initiation and predicting fracture. The Gurson-Tvergaard-Needleman (GTN) material model was applied to simulate the material failure process. Comparison of numerical simulations and test results included both global (load-displacement curves, deformations, and longitudinal stresses) and local (sequence of crack initiation and propagation, final fracture profiles) domains.

This study had two objectives considered by authors as novel. The first was to examine the application of a GTN material model to simulate the behaviour of angles connected by one leg whose resistance is based on the ultimate strength of the steel. The use of such an approach provided a better description of phenomena occurring in the failure process. The second objective was to identify the failure modes in such connections and simultaneously identify the relationship between the failure mode and the geometrical parameters describing the connection. Through experimental testing and numerical simulations, both failure mechanisms (net section and block tearing) were examined, and an approach to identify the failure mode was proposed. The obtained results contribute to the experimental and numerical evidence to validate the strength function used in future design provisions [16,17].

\section{Experimental Program}

\subsection{Test Specimens}

The experimental testing was performed on 18 equal leg angles connected by various numbers of bolts $(n=2-5)$ to the gusset plates, as shown in Figure 2 . The joints were made of two different angles $(\mathrm{L} 80 \times 80 \times 6$ and L60 $\times 60 \times 6)$ with nominal steel grade S275 The bolts were set in a single-line position. The total length of the angles depended on the number of bolts and the spacing between them, and ranged between 500 and $920 \mathrm{~mm}$.

Fully threaded bolts (M16 and M20 class 8.8 or 10.9) were used. Normal round holes with a nominal clearance of $2.0 \mathrm{~mm}$ in accordance with EN 1090-2 [18] were applied to connect the angle and gusset plates at one end of the angle, at which failure was expected. At the other end of the angle, holes with a nominal diameter equal to the shank diameter of the bolt were used. All bolt holes were formed by drilling. Washers were used under both the bolt head and nut in each assembly. Bolted connections were A category according to [19], so only snug-tightening of the bolts was applied.

Gusset plates with cross-section dimensions of $10 \mathrm{~mm} \times 100 \mathrm{~mm}$ were made from steel with nominal grade S355. The connections were designed in such a way that failure should occur only in the angle. 


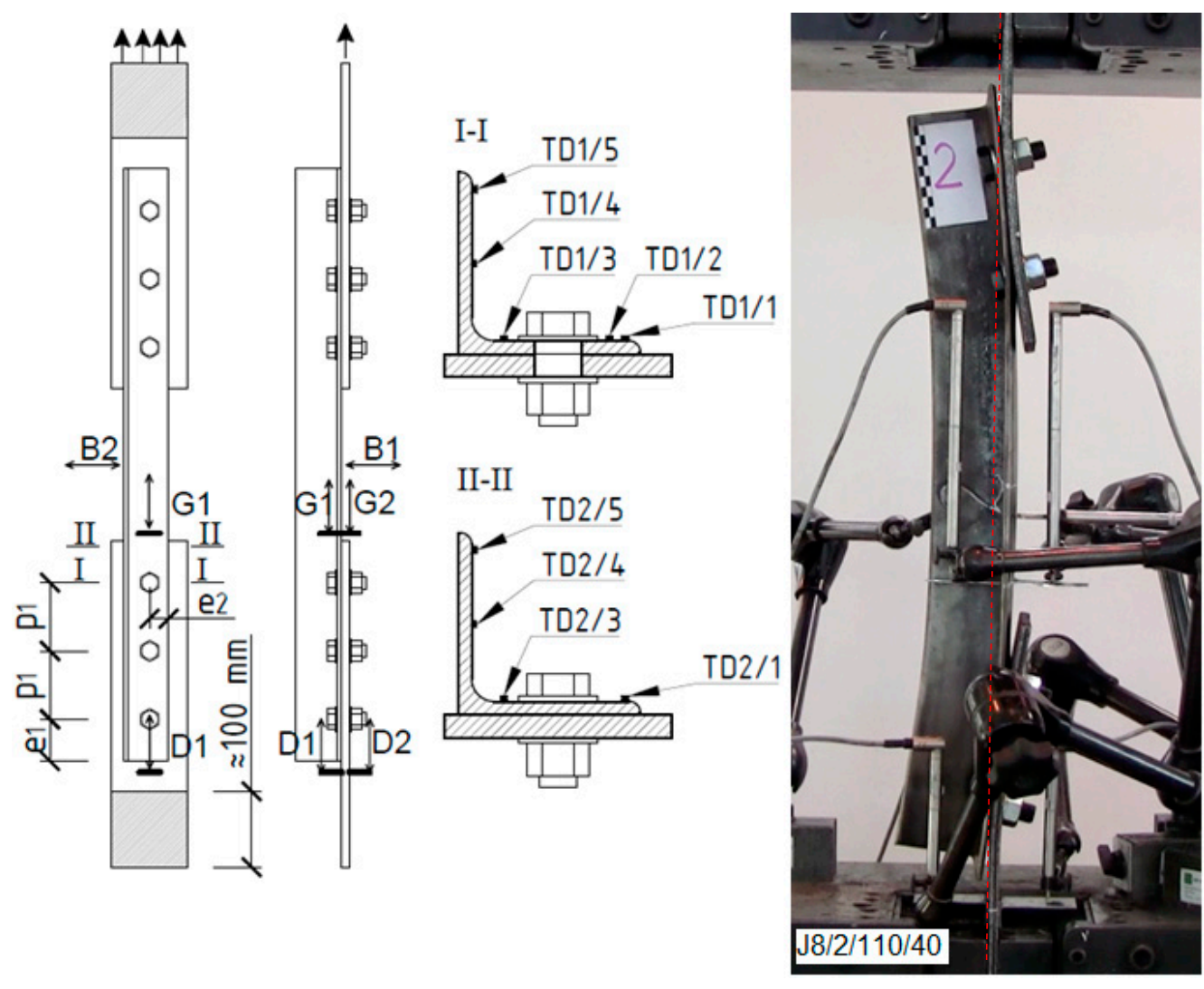

(a)

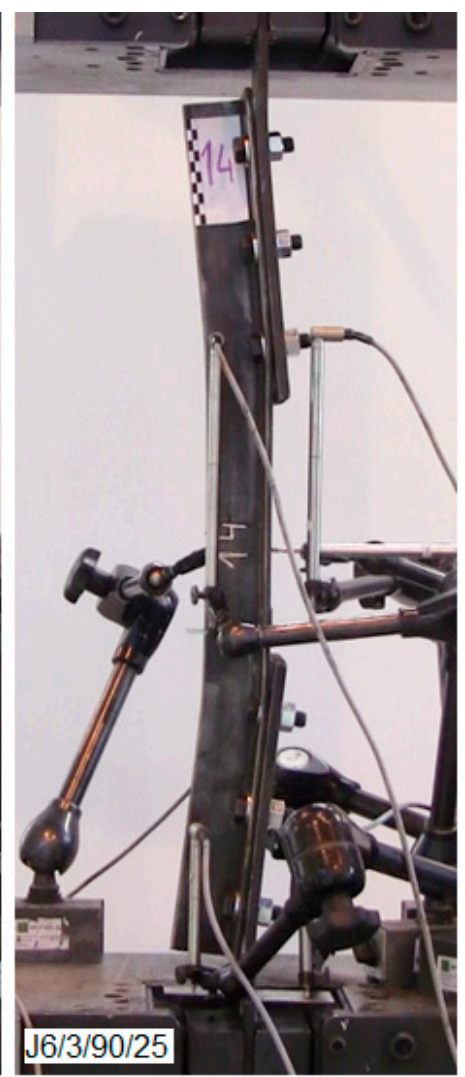

(b)

Figure 2. Test specimen: (a) placement of measuring devices, (b) test set-up.

The test parameters by which the specimens were differentiated included the dimensions of the hot-rolled angles and the $\mathrm{p}_{1}$ (bolt spacing) and $\mathrm{e}_{2}$ (edge distance in the direction perpendicular to the acting load) values. The distances $p_{1}$ were taken as $2.5 d_{0}$ or $5 d_{0}$ (these are the limit values for which the $\beta_{\mathrm{i}}$ reduction factor is different when determining the ultimate tensile resistance of an angle in accordance with [19]) or as intermediate values. Two $\mathrm{e}_{2}$ values were used for each angle size to determine whether this parameter significantly affected load capacity. A full description of the specimens is provided in Table 1.

\subsection{Test Set-Up, Instrumentation, and Procedures}

All tests were performed using an Instron $1200 \mathrm{kN-J1D}$ testing machine. The investigations consisted of a monotonic tensioning process with displacement control until the destruction of the connection. The applied load and total elongation of the specimens were measured using load cell and displacement transducers built into the testing machine. To measure joint elongation (the local vertical displacements of the angle and gusset plate in one connection), inductive displacement sensors were positioned on both sides of the specimen. Reference points $\mathrm{Gi}$ and $\mathrm{Di}$ (where $\mathrm{i}=1$ or 2 ), used during the measurements, are shown in Figure 2a. In addition, two horizontal sensors, B1 and B2, monitored the displacement of selected points in two directions in the middle of the angle length, as shown in Figure 2. Additionally, for five specimens, strain gauges TDi with working lengths of $10 \mathrm{~mm}$ or $5 \mathrm{~mm}$ were used in the net cross section of the angle (I-I) and at a short distance from it (II-II) to monitor longitudinal strains. This placed the gauges at $40 \mathrm{~mm}$ for connections with M16 bolts or $50 \mathrm{~mm}$ for those with M20s. 
Table 1. Description of test specimens.

\begin{tabular}{|c|c|c|c|c|c|c|c|c|c|}
\hline No. & Symbol & Profile & Bolts & $\underset{[\mathrm{mm}]}{\mathrm{p}_{1}}$ & $\begin{array}{c}\mathbf{e}_{1} \\
{[\mathrm{~mm}]}\end{array}$ & $\begin{array}{c}\mathbf{e}_{2} \\
{[\mathrm{~mm}]}\end{array}$ & $\begin{array}{c}\text { Observed } \\
\text { Form of } \\
\text { Failure }\end{array}$ & $\begin{array}{c}\text { Fult,Ex }_{\text {Ex }} \\
{[\mathbf{k N}]}\end{array}$ & $\mathbf{U}_{\text {eff }}[-]$ \\
\hline 1. & $\mathrm{~J} 8 / 2 / 55 / 40$ & $\mathrm{~L} 80 \times 80 \times 6$ & $2 \times \mathrm{M} 20-10.9$ & 55 & 70 & 40 & FI & 209.8 & 0.60 \\
\hline 2. & $\mathrm{~J} 8 / 2 / 110 / 40$ & $\mathrm{~L} 80 \times 80 \times 6$ & $2 \times \mathrm{M} 20-10.9$ & 110 & 70 & 40 & $\mathrm{FP}$ & 249.6 & 0.71 \\
\hline 3. & $\mathrm{~J} 8 / 2 / 55 / 30$ & $\mathrm{~L} 80 \times 80 \times 6$ & $2 \times \mathrm{M} 20-10.9$ & 55 & 70 & 30 & FI & 163.6 & 0.46 \\
\hline 4. & $\mathrm{~J} 8 / 2 / 80 / 40$ & $\mathrm{~L} 80 \times 80 \times 6$ & $2 \times \mathrm{M} 20-10.9$ & 80 & 70 & 40 & FI & 228.5 & 0.65 \\
\hline 5. & $\mathrm{~J} 8 / 2 / 80 / 30$ & $\mathrm{~L} 80 \times 80 \times 6$ & $2 \times M 20-10.9$ & 80 & 70 & 30 & FI & 184.8 & 0.53 \\
\hline 6. & $\mathrm{~J} 8 / 3 / 55 / 40$ & $\mathrm{~L} 80 \times 80 \times 6$ & $3 \times \mathrm{M} 20-8.8$ & 55 & 70 & 40 & FI & 242.1 & 0.69 \\
\hline 7. & $\mathrm{~J} 8 / 3 / 110 / 40$ & $\mathrm{~L} 80 \times 80 \times 6$ & $3 \times \mathrm{M} 20-8.8$ & 110 & 70 & 40 & FI & 283.3 & 0.81 \\
\hline 8. & $\mathrm{~J} 8 / 4 / 55 / 40$ & $\mathrm{~L} 80 \times 80 \times 6$ & $4 \times \mathrm{M} 20-8.8$ & 55 & 70 & 40 & $\mathrm{FP}$ & 268.6 & 0.77 \\
\hline 9. & $\mathrm{~J} 6 / 2 / 45 / 34$ & $\mathrm{~L} 60 \times 60 \times 6$ & $2 \times \mathrm{M} 16-8.8$ & 45 & 55 & 34 & $\mathrm{BF}$ & 179.2 & - \\
\hline 10. & $\mathrm{~J} 6 / 2 / 90 / 34$ & $\mathrm{~L} 60 \times 60 \times 6$ & $2 \times \mathrm{M} 16-10.9$ & 90 & 55 & 34 & $\mathrm{BF} / \mathrm{FI}$ & 218.2 & 0.80 \\
\hline 11. & $\mathrm{~J} 6 / 2 / 45 / 25$ & $\mathrm{~L} 60 \times 60 \times 6$ & $2 \times M 16-10.9$ & 45 & 55 & 25 & FI & 138.6 & 0.51 \\
\hline 12. & $\mathrm{~J} 6 / 2 / 90 / 25$ & $\mathrm{~L} 60 \times 60 \times 6$ & $2 \times \mathrm{M} 16-8.8$ & 90 & 55 & 25 & $\mathrm{BF}$ & 174.0 & - \\
\hline 13. & $\mathrm{~J} 6 / 3 / 45 / 25$ & $\mathrm{~L} 60 \times 60 \times 6$ & $3 \times M 16-10.9$ & 45 & 55 & 25 & FI & 180.7 & 0.66 \\
\hline 14. & $\mathrm{~J} 6 / 3 / 90 / 25$ & $\mathrm{~L} 60 \times 60 \times 6$ & $3 \times M 16-10.9$ & 90 & 55 & 25 & $\mathrm{FP}$ & 216.7 & 0.80 \\
\hline 15. & $\mathrm{~J} 6 / 4 / 45 / 34$ & $\mathrm{~L} 60 \times 60 \times 6$ & $4 \times \mathrm{M} 16-8.8$ & 45 & 55 & 34 & $\mathrm{FP}$ & 234.1 & 0.86 \\
\hline 16. & $\mathrm{~J} 6 / 4 / 70 / 34$ & $\mathrm{~L} 60 \times 60 \times 6$ & $4 \times M 16-8.8$ & 70 & 55 & 34 & $\mathrm{FP}$ & 245.5 & 0.91 \\
\hline 17. & $\mathrm{~J} 6 / 4 / 70 / 25$ & $\mathrm{~L} 60 \times 60 \times 6$ & $4 \times \mathrm{M} 16-8.8$ & 70 & 55 & 25 & FI & 224.1 & 0.82 \\
\hline 18. & $\mathrm{~J} 6 / 5 / 60 / 34$ & $\mathrm{~L} 60 \times 60 \times 6$ & $5 \times M 16-8.8$ & 60 & 55 & 34 & $\mathrm{FP}$ & 247.5 & 0.91 \\
\hline
\end{tabular}

$\mathrm{F}_{\mathrm{ult}, \mathrm{Ex}}$ - maximum tensile load registered during single test. BF-bolt failure by shear. FI-tearing from bolt hole to the edge of connected leg. FP-tearing from bolt hole to the edge of connected leg and its propagation towards outstanding leg.

\subsection{Test Results}

The material properties of the steel angles and plates used in the specimens were determined through tensile coupon tests, according to the process described in [20]. The values obtained are summarised in Table 2.

Table 2. Material properties.

\begin{tabular}{ccccc}
\hline Element & \multicolumn{2}{c}{ Yield Strength $\mathbf{f}_{\mathbf{y}}[\mathrm{MPa}]$} & \multicolumn{2}{c}{ Ultimate Strength $\mathbf{f}_{\mathbf{u}}$ [MPa] } \\
\hline & Mean Value & Standard Deviation & Mean Value & Standard Deviation \\
\hline $\mathrm{L} 80 \times 80 \times 6$ & 288 & 3.3 & 425 & 4.2 \\
$\mathrm{~L} 60 \times 60 \times 6$ & 325 & 3.7 & 470 & 2.3 \\
Gusset plate & 424 & 5.1 & 590 & 4.6 \\
\hline
\end{tabular}

During the tensioning process, significant bending deformations of the angles and gusset plates were observed. In the final stage of loading, the longitudinal axis of the angles coincided with the direction of the tensile force (Figure $2 b$ ).

In 15 of the specimens, rupture of the connected leg was observed in a net cross section at the height of the first internal bolt (cross section I-I in Figure 2a). In three specimens the shear resistance of the bolts was exceeded (marked with letters "BF" in Table 1). However, in one of these (J6/2/90/34), the shear of the bolt was accompanied by simultaneous necking, and fracture initiation was visible near the edge of the bolt hole in net cross section I-I.

Each angle rupture began from necking on the connected leg between the bolt hole and the adjacent edge (on the width described as $\mathrm{e}_{2}$ ). After visible necking occurred, tearing started from the edge of the bolt hole and propagated toward the outer edge of the connected leg. In some elements, fracture was observed only between the bolt hole and the outer edge of the connected leg (marked as "FI" in Table 1). In other elements, after rupture along the $\mathrm{e}_{2}$ distance, the fracture propagated towards the outstanding leg (this form of failure was marked as "FP" in Table 1). All failure modes were observed immediately after exceeding the ultimate load $\mathrm{F}_{\mathrm{ult}, \mathrm{Ex}}$ (maximum tensile load registered during a single test) 
and not after reaching a state of significant elongation associated with a lower load level resulting from the fracture. The observed failure modes are shown in Figure 3.

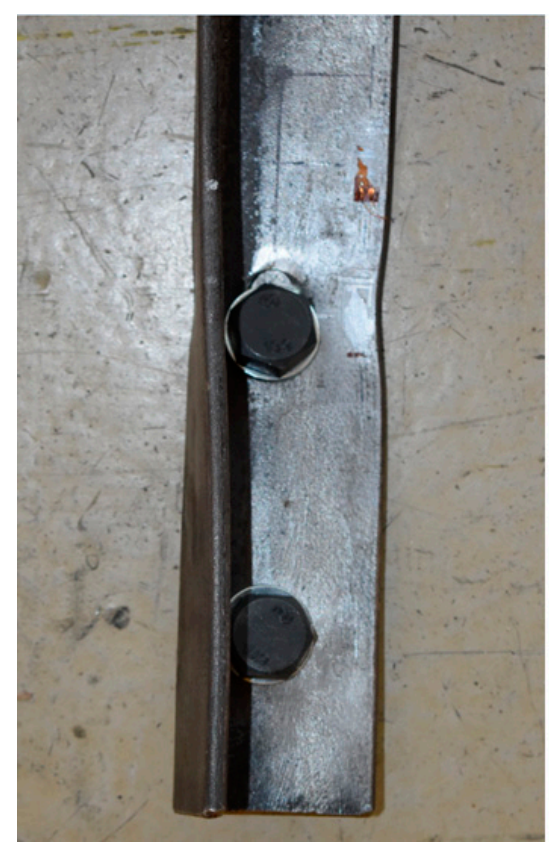

(a)

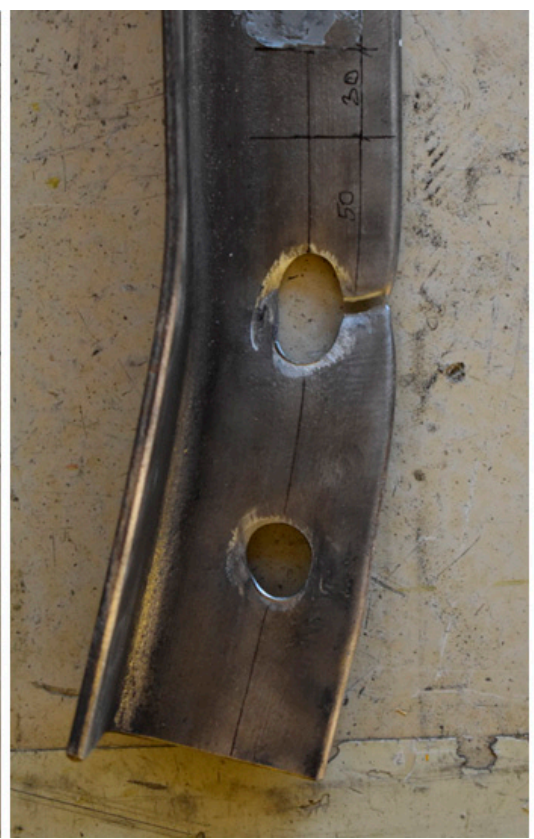

(b)

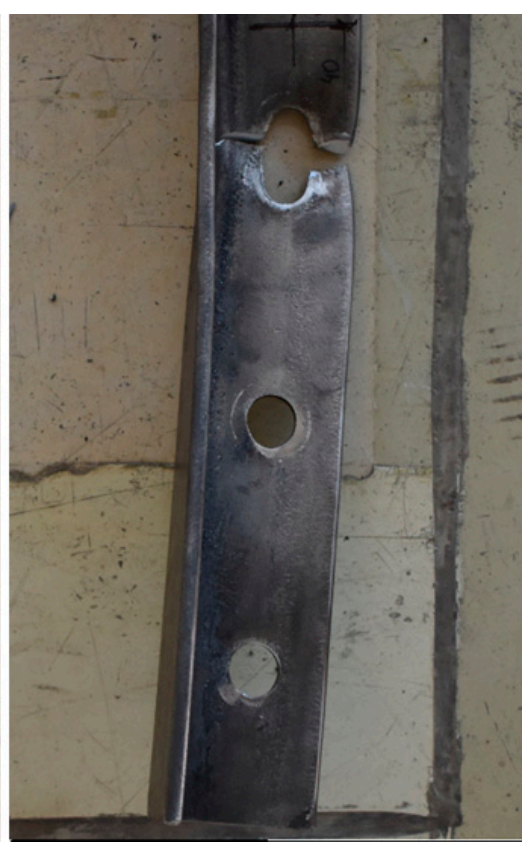

(c)

Figure 3. Failure modes of specimens: (a) shear of bolts "BF", specimen J6/2/90/34; (b) tearing across the width of connected leg "FI", specimen J8/2/80/30; (c) tearing developed towards outstanding leg “FP", specimen J6/3/90/25.

The basic data obtained from the experimental tests were the load-elongation $(\mathrm{F}-\Delta)$ curves, as presented in Figure 4, for elements where angle failure was observed. To define the elongation $\Delta$, the difference in displacement between the reference points Gi and Di was considered. Such measurements were carried out by inductive sensors positioned on both sides of the element (Figure 2) therefore, the $\Delta$ value was calculated as the arithmetic mean of the measurements on the left and right sides.

The ultimate tensile resistances $\mathrm{F}_{\mathrm{ult}, \mathrm{Ex}}$ of the specimens (which were the largest load values obtained during the test) are listed in Table 1 . For each specimen where angle failure was observed, the efficiency factor of the net cross section $U_{\text {eff }}$ was computed as follows:

$$
\mathrm{U}_{\mathrm{eff}}=\frac{\mathrm{F}_{\mathrm{ult}, \mathrm{Ex}}}{\mathrm{f}_{\mathrm{u}} \mathrm{A}_{\text {net }}}
$$

where $f_{u}$ is the ultimate strength of the angle steel, and $A_{\text {net }}$ is the net area of the angle.

This coefficient defines the extent to which the net cross section is utilised in the load transfer. The values of the $\mathrm{U}_{\text {eff }}$ coefficients are presented in Table 1 .

The tests showed the influence of the geometrical parameters on the ultimate resistance of the angles. The obtained results can be effectively used to calibrate the appropriate strength function for block tearing or for net cross-section resistance. However, the experimental tests did not precisely indicate the form of angle failure. In nearly all elements (apart from three specimens where bolt shear was observed) failure appeared through material rupture along the $\mathrm{e}_{2}$ distance, which may denote either net cross-section failure (with rupture of the net area of the whole angle $A_{\text {net }}$ ) or block tearing failure (with rupture of net area subjected to tension $\mathrm{A}_{\mathrm{nt}}$ ). In a few specimens, the fracture propagated towards the outstanding leg (which can be assumed as the net cross-section failure mode), but this phenomenon can also be explained as the effect of the dynamic process of fracture. To examine the failure process and assign a proper failure mode, it was necessary to conduct numerical simulations. 


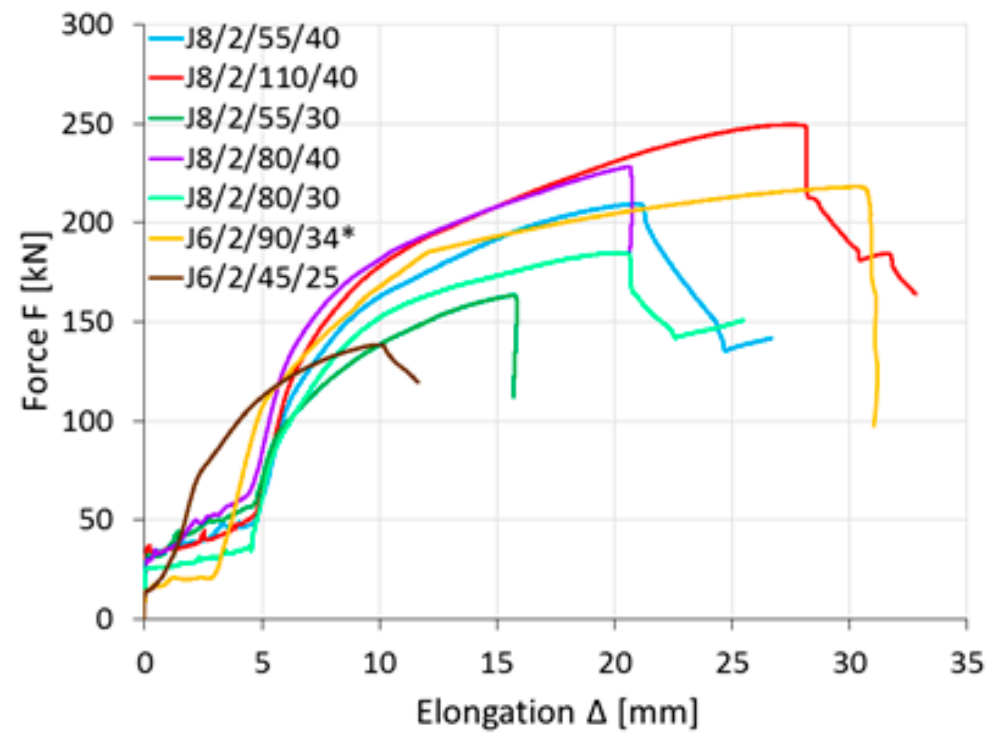

(a)

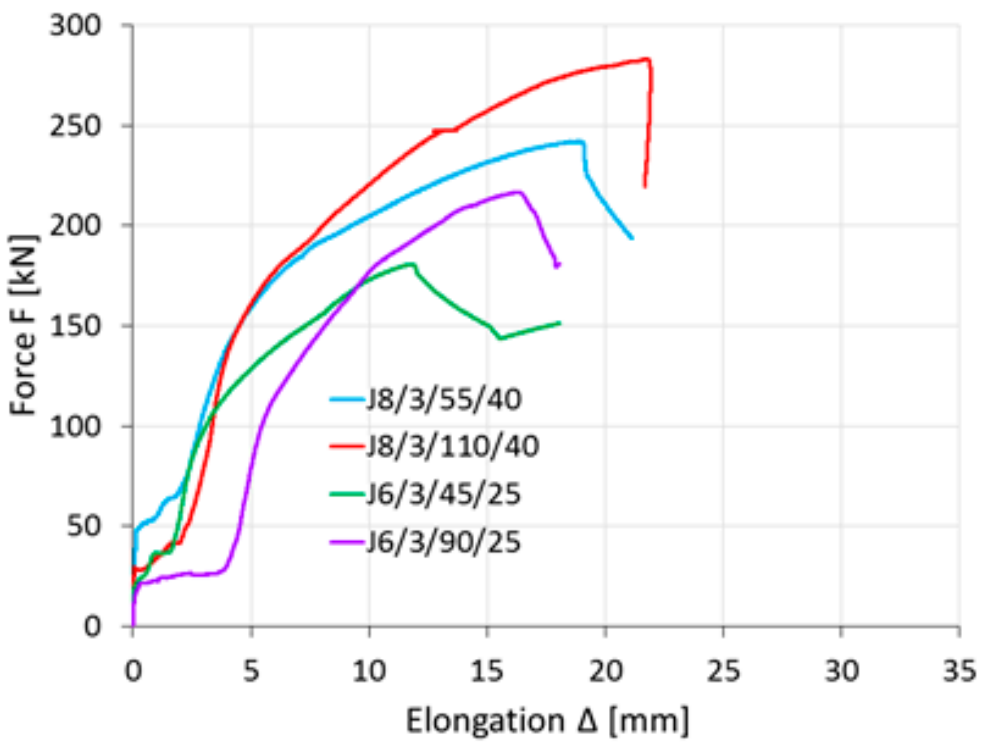

(b)

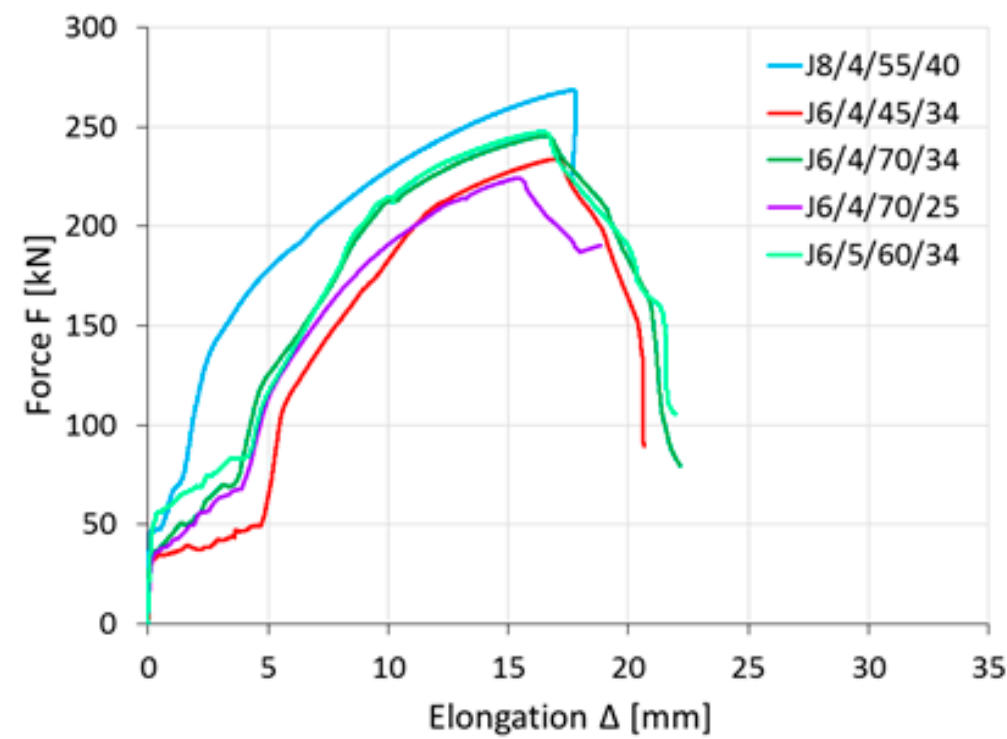

(c)

Figure 4. Load-elongation diagrams: (a) connections with 2 bolts, (b) connections with 3 bolts, (c) connections with 4 or more bolts $\left({ }^{*}\right.$ : elongation in this case was measured by machine clamps). 


\section{Finite Element Analysis}

\subsection{Material Model}

Finite element analysis of steel component failure triggered by yielding and ductile crack initiation is a different process compared to the well-established approaches for predicting stability or plastic resistance. Many assessment strategies can be applied, considering the balance between accuracy and cost [21,22]. To model the material failure process, the GTN material model was chosen. This model is intended for use in fracture or damage analysis, and its purpose is to predict ductile crack behaviour through void growth and coalescence [23]. This is a micromechanical, model-based approach that can be effectively employed in structural components without sharp cracks, e.g., in zones of stress concentration around holes. Many studies [24-27] have shown that the use of the GTN model in the analysis of such structural steel elements yields satisfactory results. However, the application of such an approach to simulate the behaviour of elements in lap bolted joints under tension is limited.

For metals, the process of crack initiation and propagation is associated with damage to the material microstructure. These defects, in the form of voids, appear at non-metallic inclusions or precipitates of another phase present in the material. During deformation, the voids grow and connect in a process called coalescence, creating a crack. The ductile fracture mechanism is shown in Figure 5.

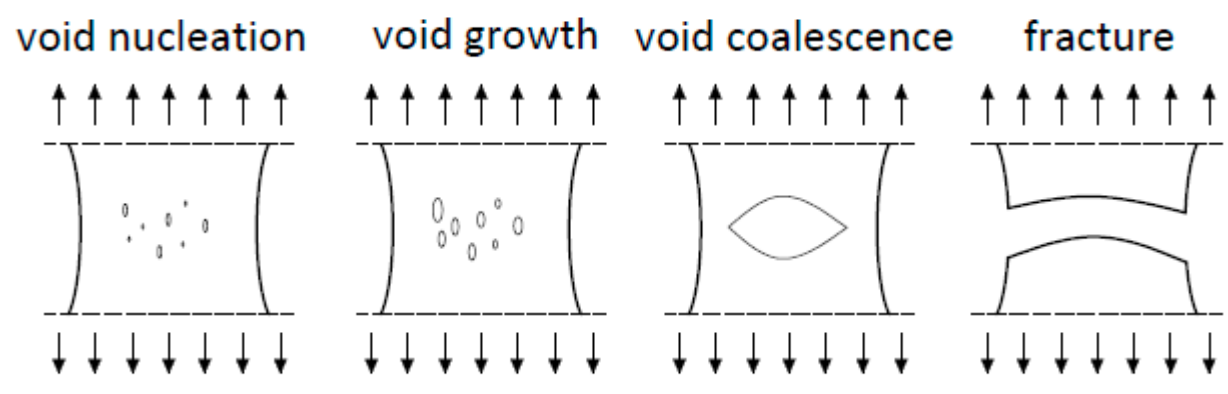

Figure 5. Mechanism of ductile fracture.

Therefore, the material strength, defined by the normal stress $\sigma$, is closely related to its damage. The stress value begins to decrease at the moment of void initiation. Void growth causes softening of the material and leads to its destruction when the critical value is reached [26].

According to the GTN material model, the failure criterion is defined as follows:

$$
\Phi=\left(\frac{\sigma_{\text {eff }}}{\sigma_{0}}\right)^{2}+2 q_{1} f^{*} \cosh \left(q_{2} \frac{3 \sigma_{\mathrm{m}}}{2 \sigma_{0}}\right)-\left(1+q_{3} f^{* 2}\right)=0
$$

where $\Phi$ is the non-dilatational strain energy; $\sigma_{\text {eff }}$ is the effective stress according to the Huber-Mises-Hencky hypothesis; $\sigma_{0}$ is the material yield stress; $\sigma_{\mathrm{m}}$ is the hydrostatic pressure (mean stress); $f^{*}$ is the modified void volume fraction, and $q_{\mathrm{i}}$ is the Tvergaard parameters describing the plastic properties of the material.

The modified void volume fraction $f^{*}$ describes the microstructural properties of the material and is defined as follows:

$$
f^{*}=\left\{\begin{array}{c}
f \quad \text { for } f \leq f_{\mathrm{c}}, \\
f_{\mathrm{c}}+\frac{\overline{f_{\mathrm{F}}}-f_{\mathrm{c}}}{\bar{f}_{\mathrm{F}}-f_{\mathrm{c}}}\left(f-f_{\mathrm{c}}\right) \text { for } f_{\mathrm{c}}<f<f_{\mathrm{F}}, \\
f_{\mathrm{F}} \text { for } f \geq f_{\mathrm{F}} .
\end{array}\right.
$$

where $f$ is the current void volume fraction; $f_{\mathrm{c}}$ is the critical void volume fraction at which the void coalescence starts, and $f_{\mathrm{F}}$ is the void volume fraction corresponding to 
the complete loss of the material strength at the final separation of the material; $\overline{f_{\mathrm{F}}}=$ $\left(q_{1}+\sqrt{q_{1}^{2}-q_{3}}\right) / q_{3}$.

When the material is not subjected to a load, the modified void volume fraction is equal to the initial void volume fraction $f_{0}$. This is the basic parameter of the GTN model related to material porosity. The value of $f_{0}$ can be determined using Franklin's formula, as shown in Equation (4), on the basis of the chemical composition [22], where $\mathrm{Mn} \%$ and $\mathrm{S} \%$ are the percentages of manganese and sulphur inclusions. These values are determined according to the standard defined in [28] or on the basis of microstructure tests in which the non-metallic inclusions and precipitates of a different phase are counted in relation to the surface of the tested specimen.

$$
f_{0}=0.054\left(\mathrm{~S} \%-\frac{0.001}{\mathrm{Mn} \%}\right)
$$

The critical void volume fraction $\mathrm{fc}$ is related to the value of $f_{0}$ [27], but it can also be determined by fitting the F- $\Delta$ curve obtained from numerical simulations to that obtained from experimental tests, or using microscopic photography [29]. The value of $f_{\mathrm{F}}$ corresponds to the criterion of material failure, and for metals ranges from $0.10-0.20$. This can also be experimentally determined [30].

The Tvergaard parameters $q_{\mathrm{i}}$ influence the strength properties of the material. They are material constants to approximate the real structural behaviour (to better represent the void interaction effect). The optimal proposed values for many metals, including steel, are $q_{1}=1.5, q_{2}=1.0$ and $q_{3}=q_{1}^{2}=2.25$.

The damage evolution is described by the following material parameters: $f_{N}, \varepsilon_{N}$, and $s_{\mathrm{N}}$. The first describes the volume fraction of nucleated voids, which for structural steels is assumed to be 0.04 . The strain related to formation of new voids is called the mean strain of void nucleation, $\varepsilon_{N}$. The typical value for structural steel is $\varepsilon_{N}=0.30$. The GTN model assumes a normal distribution of void nucleation strain and a standard deviation $s_{\mathrm{N}}$ ranging from $0.01-0.10$.

Hierarchical validation of the material model used in the analysis was conducted as described in [31]. The final values of the GTN parameters introduced to the Abaqus program, after recognition of the available data and calibration, are presented in Table 3.

Table 3. GTN material parameters introduced to numerical simulations.

\begin{tabular}{ccccccc}
\hline$f_{0}$ & Tvergaard Parameters $q_{\mathrm{i}}$ & $f_{\mathrm{c}}$ & $f_{\mathrm{F}}$ & $f_{\mathbf{N}}$ & $\varepsilon_{\mathbf{N}}$ & $s_{\mathbf{N}}$ \\
\hline 0.01 & $q_{1}=1.5 ; q_{2}=1.0 ; q_{3}=2.25$ & 0.06 & 0.2 & 0.02 & 0.3 & 0.1 \\
\hline
\end{tabular}

\subsection{Analysis Method}

The commercial software package Abaqus [32] was used to perform the FE analyses. Modelling covered the entire group of tested elements (see Table 1). Only those elements where the failure was visually determined to be caused by bolt shear were omitted. Each FE model consisted of four components: angle, gusset plates, washers, and bolts modelled together with nuts. Part of one gusset plate had blocked displacement in all directions (corresponding to the machine clamps). The load in the z-direction in the form of displacement was applied to the second gusset plate, which had blocked $\mathrm{x}$ - and $\mathrm{y}$ - displacements on the clenched part. Initially, both washers and bolts were located concentrically with the bolt holes in the angle and gusset plates. Figure 6 presents the view of the complete model with an FE mesh and boundary conditions.

For angles, gusset plates, and washers, a C3D8R type of element was employed, i.e., a three-dimensional hexahedral eight-node linear brick with reduced integration. This type of element has proved to be suitable for simulating lap bolted connections $[33,34]$. In the vicinity of the bolt holes where stress concentration was expected, the mesh was appropriately dense. 


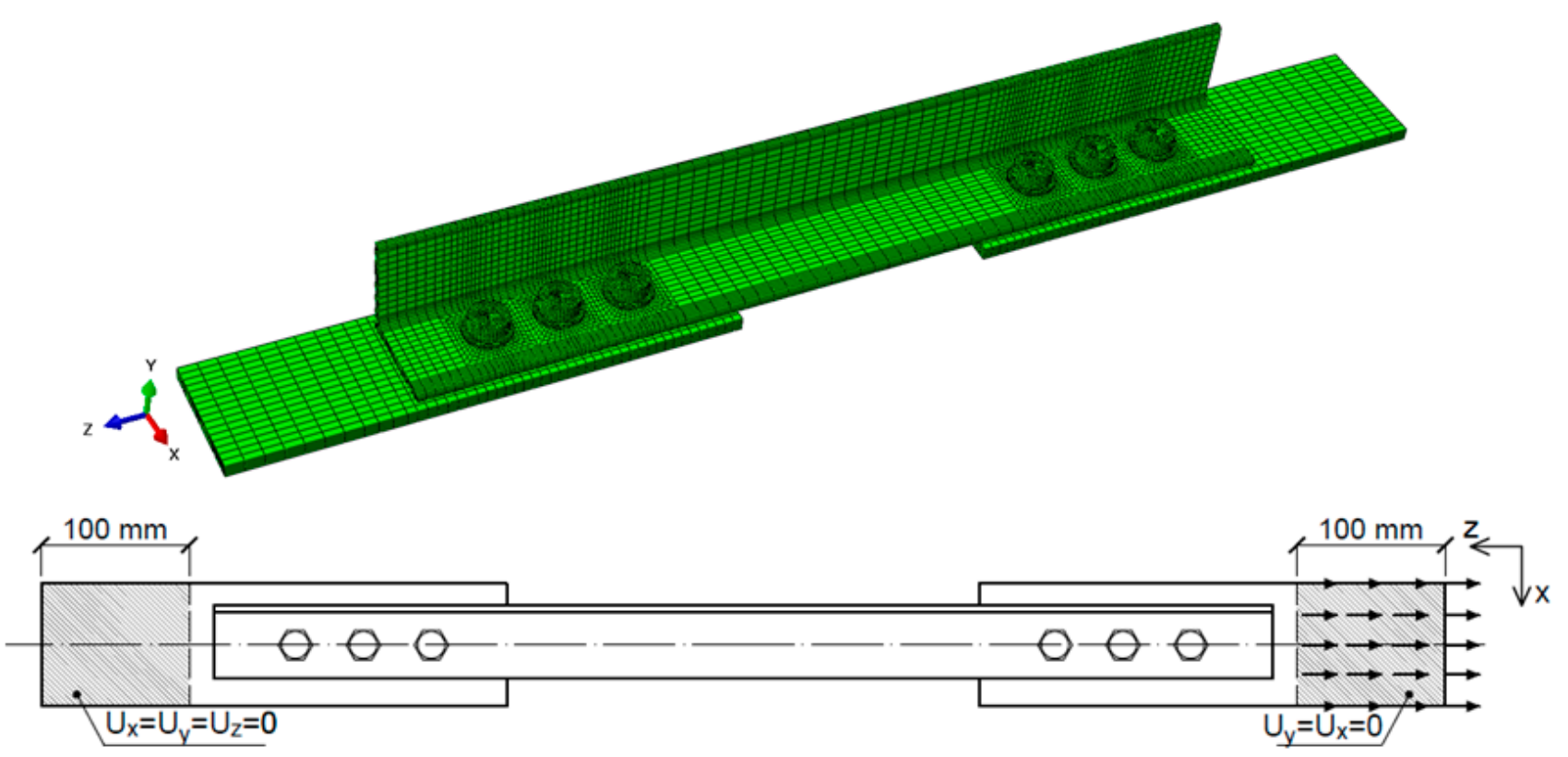

Figure 6. Finite element model and applied boundary conditions.

Bolts were built using C3D8T and C3D6T elements, which are eight-node thermally coupled bricks with trilinear displacement and temperature and six-node thermally coupled triangular prisms, respectively. To apply a small clamping force starting from snugtightened bolts, a vertical thermal deformation method was utilised [35]. The bolt shank was modelled as a smooth cylinder with a diameter equal to the nominal diameter of the bolt for both the M16 and M20 bolts. The bolt thread was not modelled in the shank.

Contact conditions were applied to simulate the interaction between the angles, bolts, washers, and gusset plates. Contact between surfaces was defined using the general contact option [32]. The frictional effects between surfaces were also included by incorporating the classical isotropic Coulomb friction model in the contact definition, with a friction coefficient $\mu$ equal to 0.1 .

For angle elements where fracture was expected, the GTN material model was applied with the parameters shown in Table 3. For the remaining elements (gusset plates, washers, and bolts), an elastic-plastic multilinear material model was implemented. The main material properties, such as yield strength and ultimate strength, were obtained from tests (see Table 2).

Implementation of the GTN porous material model required dynamic explicit analysis with a displacement-based control algorithm.

\subsection{Comparison of FE Model Results with Tests in Global Terms}

Figures 7-9 show, for selected elements, a comparison between the numerical models and the experimental tests in the load-elongation measure $\mathrm{F}-\Delta$ (the displacement difference between reference points). These figures also show obtained global deformation of specimens during experimental and numerical tests at the same load level $\mathrm{F}$.

Table 4 compares the simulation values of the maximum tensile load $\mathrm{F}_{\mathrm{ult}, \mathrm{FEM}}$ and elongation $\mathrm{L}_{\mathrm{ult}, \text { FEM }}$ to the corresponding values from experimental tests $\left(\mathrm{F}_{\mathrm{ult}, \mathrm{Ex}}\right.$ and $\left.\mathrm{L}_{\mathrm{ult}, \mathrm{Ex}}\right)$. The elongation $\mathrm{L}_{\mathrm{ult}, \mathrm{FEM}}$ (or $\mathrm{L}_{\mathrm{ult}, \mathrm{Ex}}$ ) refers to the point on the $\mathrm{F}-\Delta$ curves where the maximum load $\mathrm{F}_{\mathrm{ult}, \mathrm{FEM}}\left(\right.$ or $\mathrm{F}_{\mathrm{ult}, \mathrm{Ex}}$ ) was obtained (see Figure $7 \mathrm{c}$ ). The factors $\Delta_{\mathrm{F}}$ and $\Delta_{\mathrm{L}}$ denote the relative difference between the results from simulations and tests, calculated according to Equation (5).

$$
\Delta_{\mathrm{F}}=\frac{\mathrm{F}_{\mathrm{ult}, \mathrm{FEA}}-\mathrm{F}_{\mathrm{ult}, \mathrm{Ex}}}{\mathrm{F}_{\mathrm{ult}, \mathrm{Ex}}} ; \Delta_{\mathrm{L}}=\frac{\mathrm{L}_{\mathrm{ult}, \mathrm{FEA}}-\mathrm{L}_{\mathrm{ult}, \mathrm{Ex}}}{\mathrm{L}_{\mathrm{ult}, \mathrm{Ex}}}
$$




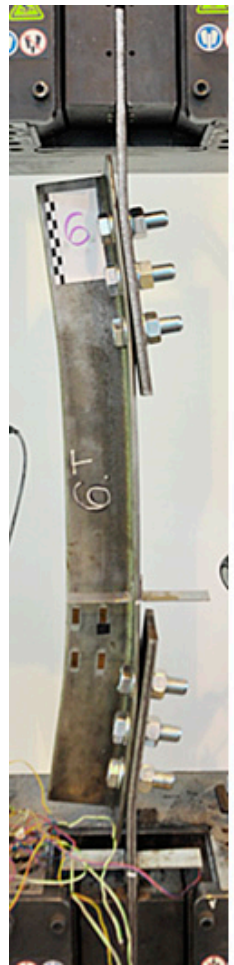

(a)

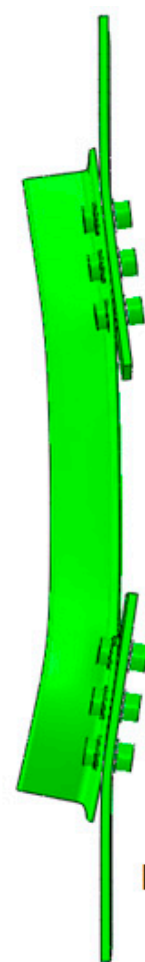

(b)

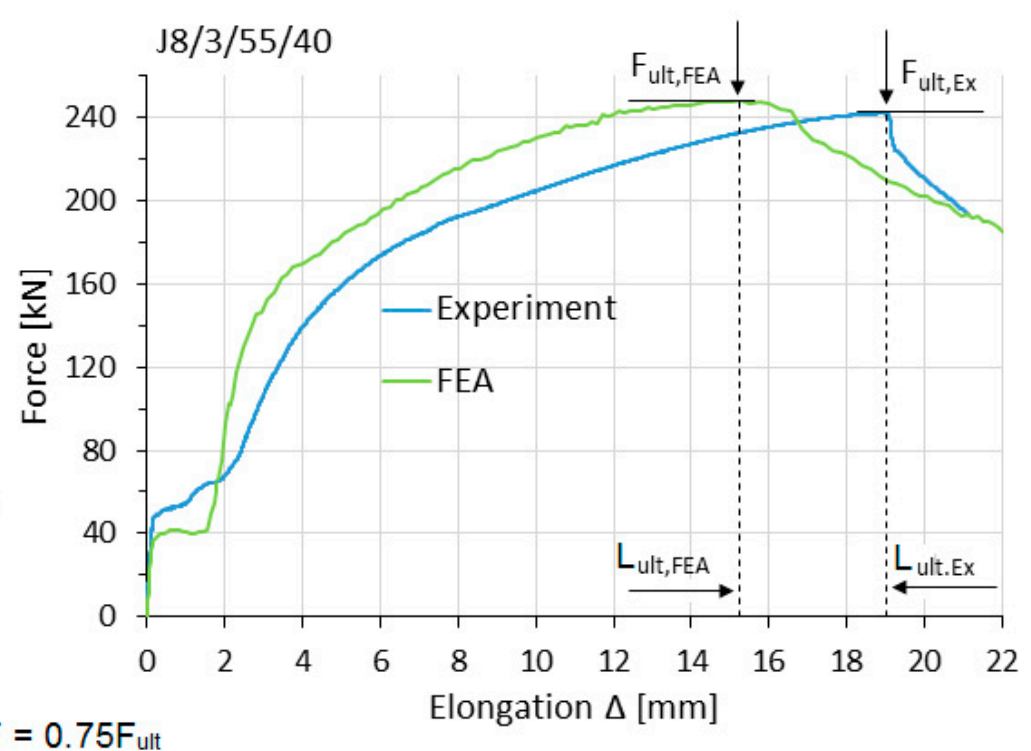

(c)

Figure 7. Specimen J8/3/55/40 in the failure phase: (a) experiment, (b) FE analysis (FEA) model, (c) F- $\Delta$ curves.

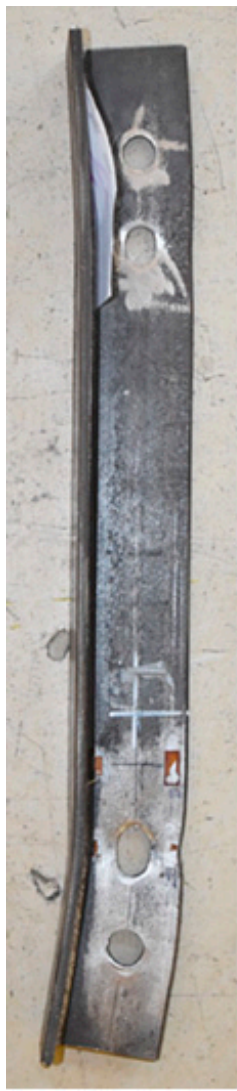

(a)

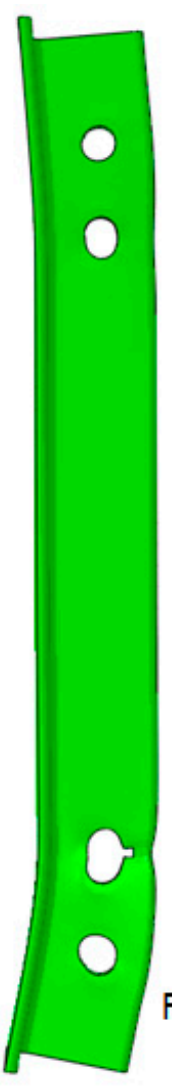

(b)
$J 6 / 2 / 45 / 25$

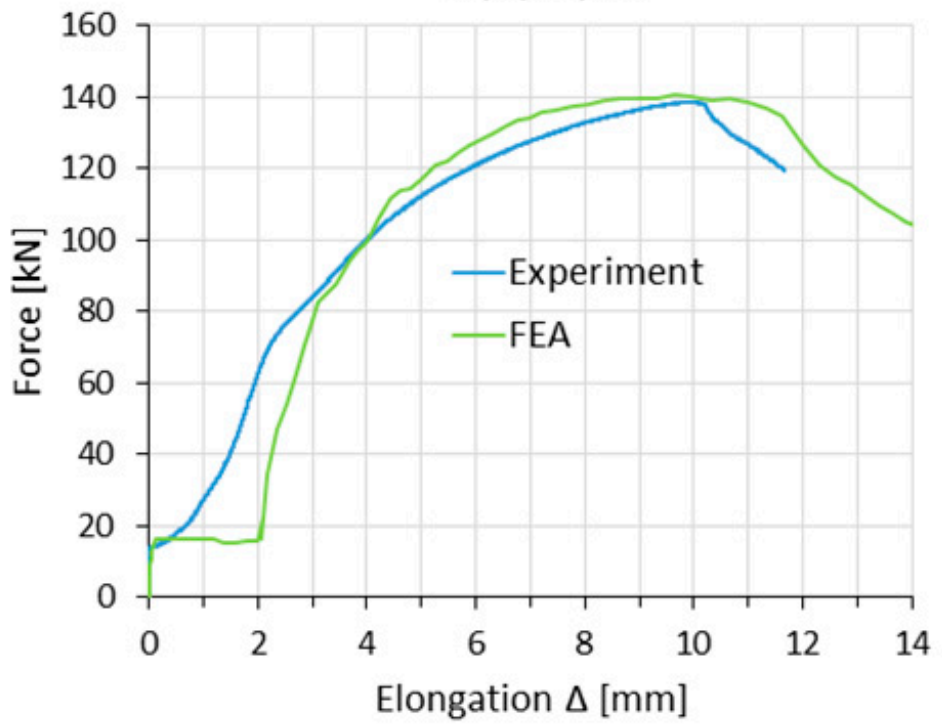

$\mathrm{F}=0$ (after unloading) (c)

Figure 8. Specimen J6/2/45/25 after fracture: (a) experiment, (b) FEA model, (c) F- $\Delta$ curves. 


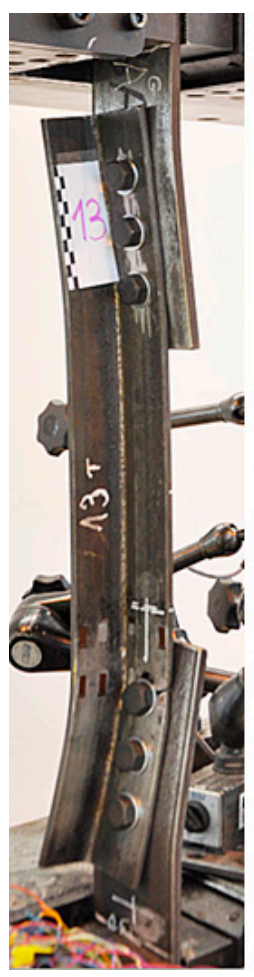

(a)

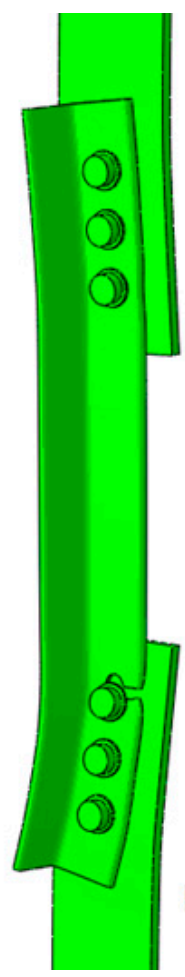

(b)

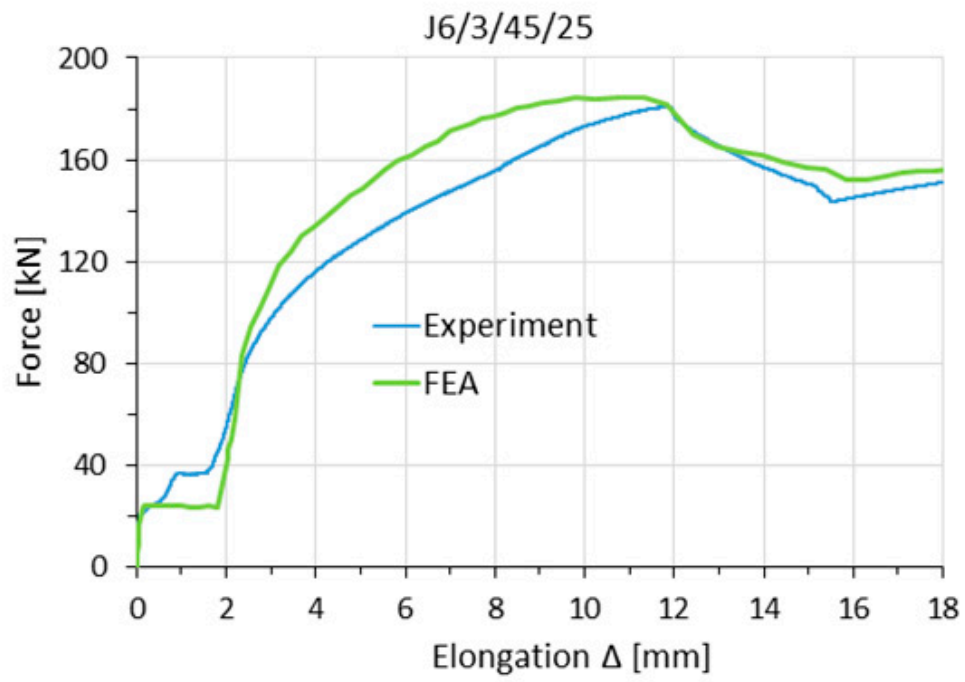

$\mathrm{F}=0.85 \mathrm{~F}_{\mathrm{ult}}$

Figure 9. Specimen J6/3/45/25 in the failure phase: (a) experiment, (b) FEA model, (c) F- $\Delta$ curves.

Table 4. Comparison of tensile resistance and elongation obtained from experimental tests and numerical simulations.

\begin{tabular}{|c|c|c|c|c|c|c|c|}
\hline No. & Symbol & $\begin{array}{l}\text { Fult,Ex }_{\text {ex }} \\
{[\mathrm{kN}]}\end{array}$ & $\begin{array}{c}\text { F }_{\text {ult,FEA }} \\
{[\mathbf{k N}]}\end{array}$ & $\Delta_{\mathrm{F}}[-]$ & $\begin{array}{l}\mathrm{L}_{\mathrm{ult}, \mathrm{Ex}} \\
{[\mathrm{mm}]}\end{array}$ & $\begin{array}{c}\text { L }_{\text {ult,FEA }} \\
{[\mathrm{mm}]}\end{array}$ & $\Delta_{\mathrm{L}}[-]$ \\
\hline 1. & $\mathrm{~J} 8 / 2 / 55 / 40$ & 209.8 & 200.4 & -0.04 & 20.8 & 14.0 & -0.33 \\
\hline 2. & $\mathrm{~J} 8 / 2 / 110 / 40$ & 249.6 & 245.9 & -0.02 & 27.3 & 21.6 & -0.21 \\
\hline 3. & $\mathrm{~J} 8 / 2 / 55 / 30$ & 163.6 & 158.2 & -0.03 & 15.7 & 10.4 & -0.34 \\
\hline 4. & $\mathrm{~J} 8 / 2 / 80 / 40$ & 228.5 & 227.5 & -0.004 & 20.6 & 18.1 & -0.12 \\
\hline 5. & $\mathrm{~J} 8 / 2 / 80 / 30$ & 184.8 & 179.6 & -0.03 & 19.8 & 12.6 & -0.37 \\
\hline 6. & $\mathrm{~J} 8 / 3 / 55 / 40$ & 242.1 & 248.1 & 0.02 & 18.8 & 15.3 & -0.19 \\
\hline 7. & $\mathrm{~J} 8 / 3 / 110 / 40$ & 283.3 & 294.4 & 0.04 & 21.8 & 15.3 & -0.30 \\
\hline 8. & $\mathrm{~J} 8 / 4 / 55 / 40$ & 268.6 & 283.8 & 0.06 & 17.7 & 14.8 & -0.16 \\
\hline 9. & $\mathrm{~J} 6 / 2 / 45 / 34$ & & n.a. & n.a. & & n.a. & n.a. \\
\hline 10. & $\mathrm{~J} 6 / 2 / 90 / 34$ & 218.2 & 214.3 & -0.02 & $30.8 *$ & 16.8 & n.a. \\
\hline 11. & $\mathrm{~J} 6 / 2 / 45 / 25$ & 138.6 & 140.8 & 0.02 & 9.9 & 9.6 & -0.03 \\
\hline 12. & $\mathrm{~J} 6 / 2 / 90 / 25$ & & n.a. & n.a. & & n.a. & n.a. \\
\hline 13. & $\mathrm{~J} 6 / 3 / 45 / 25$ & 180.7 & 184.4 & 0.02 & 11.4 & 10.4 & -0.09 \\
\hline 14. & $\mathrm{~J} 6 / 3 / 90 / 25$ & 216.7 & 226.7 & 0.05 & 16.9 & 11.5 & -0.32 \\
\hline 15. & $\mathrm{~J} 6 / 4 / 45 / 34$ & 234.1 & 242.5 & 0.04 & 17.0 & 12.1 & -0.29 \\
\hline 16. & $\mathrm{~J} 6 / 4 / 70 / 34$ & 245.5 & 255.4 & 0.04 & 16.6 & 11.9 & -0.28 \\
\hline 17. & $\mathrm{~J} 6 / 4 / 70 / 25$ & 224.1 & 229.1 & 0.02 & 15.4 & 8.7 & -0.44 \\
\hline \multirow[t]{3}{*}{18.} & $\mathrm{~J} 6 / 5 / 60 / 34$ & 247.5 & 248.1 & 0.002 & 16.4 & 10.9 & -0.34 \\
\hline & & \multicolumn{2}{|c|}{ Mean value } & 0.01 & & & $-0.25 * *$ \\
\hline & & \multicolumn{2}{|c|}{ Standard deviation } & 0.03 & & & $0.12 * *$ \\
\hline
\end{tabular}

*: displacement measured by machine clamps. ${ }^{* *}$ : results excluding J6/2/90/34 element. n.a.: not analysed because of bolt failure. 
For the purpose of validation, measurement results obtained from inductive sensors recording lateral displacements at B1 and B2 (Figure 10) and strain gauges (Figure 11) were also used. For several load levels (from $10 \%$ to $100 \% \mathrm{~F}_{\text {ult,FEM), appropriate values were }}$ obtained from computational models and marked as points on the graphs.
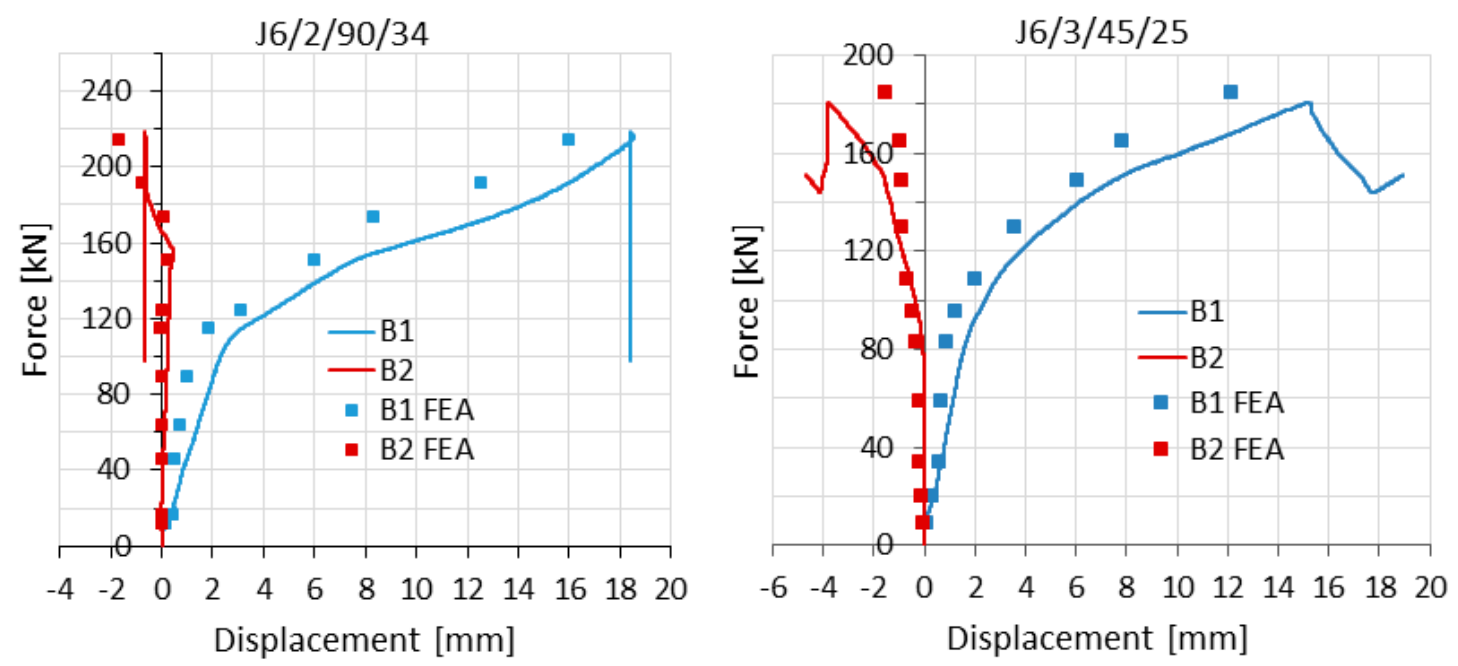

Figure 10. Load-horizontal displacement curves gained from experimental tests and numerical simulations for example elements.
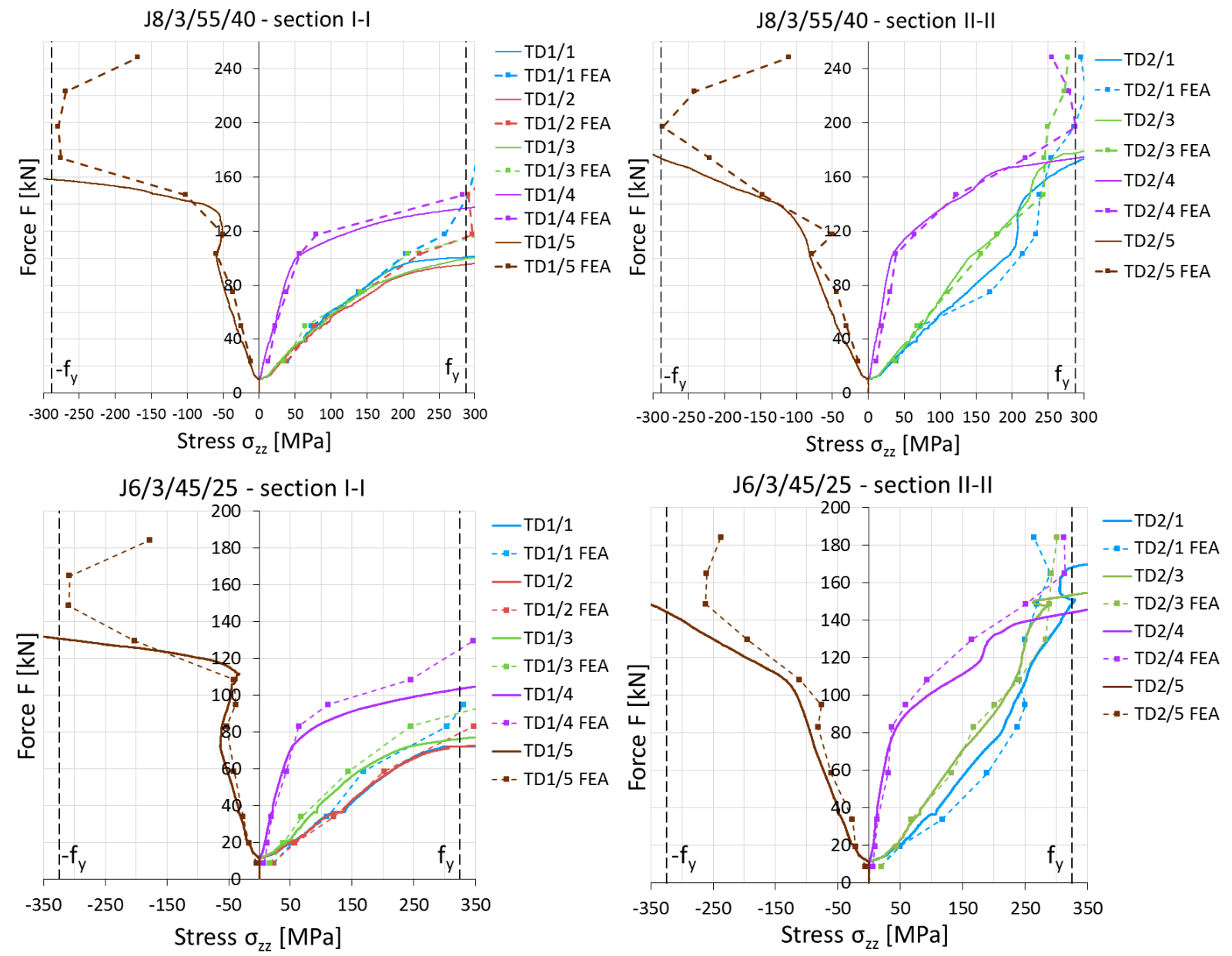

Figure 11. Comparison of longitudinal stress $\sigma_{\mathrm{zz}}$ values obtained from experimental tests and numerical simulations for example elements. 
The numerical model predicted the ultimate tensile resistance with high accuracy. The mean value of the relative difference $\Delta_{F}$ for the whole group of tested specimens was 0.01 with a standard deviation of 0.03 . The predicted global deformation of the elements under load and stress corresponded to the actual connection reactions.

However, the numerical models were characterised by lower elongation compared to the experiments. The mean value of the relative difference $\Delta_{\mathrm{L}}$ (excluding element J6/2/90/34 for which elongation was measured by machine clamps) was -0.25 with a standard deviation of 0.12 . The greater deformation of the test connections compared to those of the FE models can be explained by the influence of the bolt threads (not included in the FE model) and the non-concentric alignment of the bolts and bolt holes in the tested specimens.

\section{Observed Failure Mechanism}

The final fracture profiles obtained during the FE analyses were very close to those observed during the experiment (Figure 12).

The sequence of crack initiation and propagation obtained in the numerical analyses (shown in Figure 13) was also identical to that observed during the tests.

However, the ductile fracture propagation and its final position in the angle did not conclusively determine the failure mode. All fractures (in both testing and FE modelling) occurred or started between the bolt hole and the outer edge of the connected leg. This area coincided with the fracture area in block tearing (net area subjected to tension $A_{n t}$ ) and the net area of the whole angle $A_{\text {net, }}$ which controls the net cross-section failure. Therefore, to define which failure mode controlled the rupture process, the distribution of effective stresses ( $\sigma_{\text {eff }}$, according to the Huber-Mises-Hencky hypothesis) in the net cross-section $\mathrm{A}_{\text {net }}$ and in the section under block tearing in all specimens was observed. The net cross section was considered along perpendicular lines A-D and D-E across the first internal bolt hole, as shown in Figure 14a. The section subject to block tearing was considered to be line $A-B$, crossing the net area subject to tension $A_{n t}$, and the line starting from point $F$ and ending in point $M$, defining the net area subject to shear $A_{n v}$, as shown in Figure $14 b$. The distribution of effective stress was also considered to be along line $A-B$, crossing the net area subject to tension $A_{n t}$, and the line between points $\mathrm{F}^{\prime}$ and $\mathrm{J}^{\prime}$, defining the gross area subject to shear $\mathrm{A}_{\mathrm{gv}}$ (Figure 14c).

For all specimens the effective stress $\sigma_{\text {eff }}$ along the A-B section was very similar; the values reached the ultimate strength of the steel. At the level of loading equal to $\mathrm{F}_{\mathrm{ult}, \mathrm{FEA}}$, there was a slight drop in stress on both sides of line A-B after reaching the ultimate strength value. Therefore, only verification of the effective stress distribution along the section subject to shear could distinguish between the failure modes.

Three different types of effective stress distribution were observed in these areas. In six specimens, effective stresses along the total length of the net cross section F-M or gross cross section $\mathrm{F}^{\prime}-\mathrm{J}^{\prime}$ achieved or exceeded the yield stress value $\mathrm{f}_{\mathrm{y}}$, as shown in Figure 15a. This distribution clearly indicated the occurrence of block tearing (BT). For four angles, the effective stresses along F-M or $\mathrm{F}^{\prime}-\mathrm{J}^{\prime}$ did not fully reach the yield stress $\mathrm{f}_{\mathrm{y}}$, especially in the area between the bolts, which suggests that net section tearing (NT) was the cause of failure, as shown in Figure 15b. For the other six elements, the effective stress reached the yield stress along the net or gross area subject to shear, but only between the bolts. Along the end distance $e_{1}$ (from the bolt to the adjacent end of the angle, measured in the direction of load transfer), the shear area was not fully yielded. Hence, these elements were classified as subject to a limited block tearing failure mode (BT-L) (Figure 15c).

A comparison between failure modes observed during experimental tests and simulated in analyses (based on the distribution of effective stress along shear area) is shown in Table 5 . 

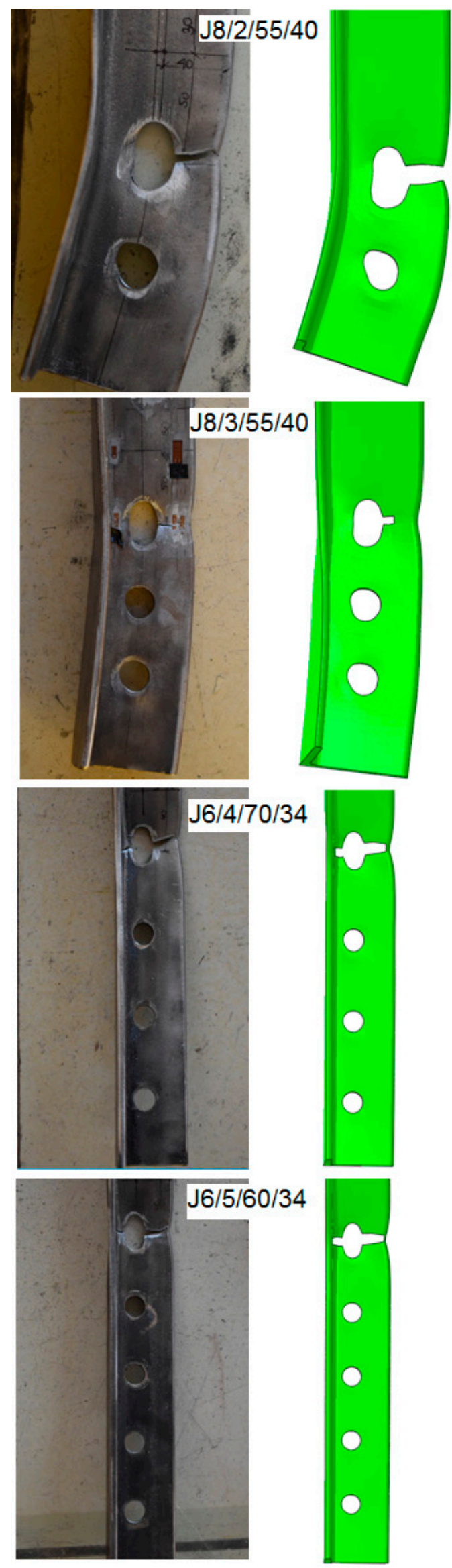

Figure 12. Comparison of failure modes observed in testing and FE modelling. 

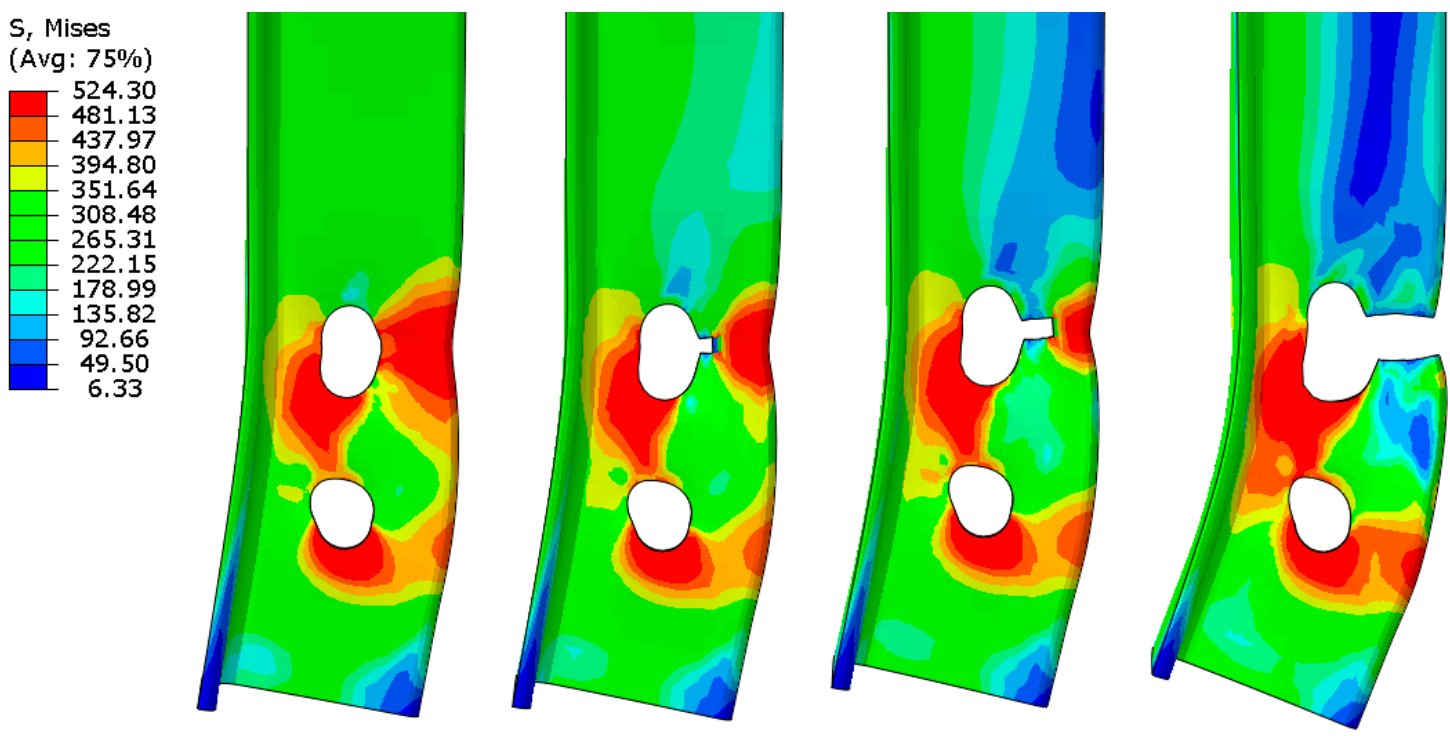

Figure 13. Fracture sequence obtained in FE modelling (specimen J8/2/55/40).

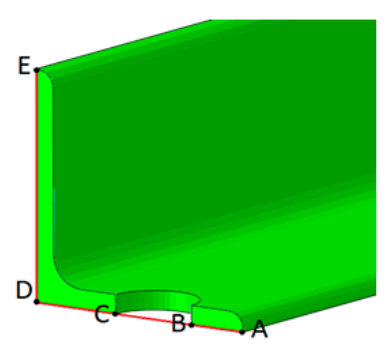

(a)

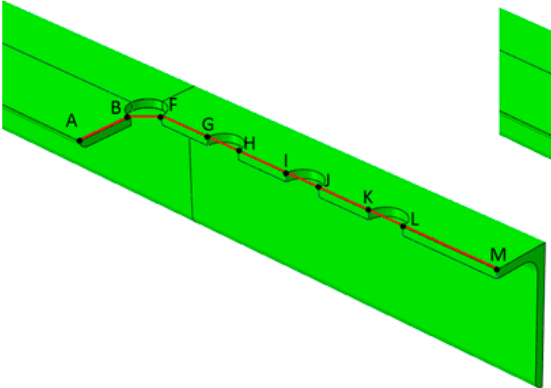

(b)

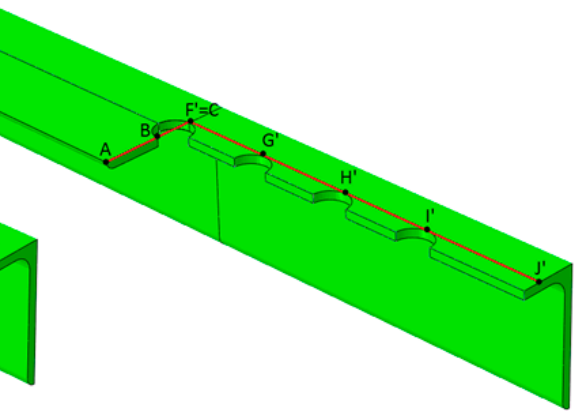

(c)

Figure 14. Path definitions: (a) in net cross section, (b) in block tearing-section along net cross section $A_{n v}$, (c) in block tearing-section along gross cross section $\mathrm{A}_{\mathrm{gv}}$.

Table 5. Comparison of failure modes obtained from experimental tests and numerical simulations.

\begin{tabular}{cccc}
\hline \multirow{2}{*}{ No. } & Symbol & \multicolumn{2}{c}{ Failure Mode } \\
\cline { 3 - 4 } & & Test & FE Modelling \\
\hline 1. & $\mathrm{~J} 8 / 2 / 55 / 40$ & FI & BT-L \\
2. & $\mathrm{~J} 8 / 2 / 110 / 40$ & FP & BT \\
3. & $\mathrm{~J} 8 / 2 / 55 / 30$ & FI & BT-L \\
4. & $\mathrm{~J} 8 / 2 / 80 / 40$ & FI & BT-L \\
5. & $\mathrm{~J} 8 / 2 / 80 / 30$ & FI & BT-L \\
6. & $\mathrm{~J} 8 / 3 / 55 / 40$ & FI & BT \\
7. & $\mathrm{~J} 8 / 3 / 110 / 40$ & FI & BT \\
8. & $\mathrm{~J} 8 / 4 / 55 / 40$ & FP & BT \\
9. & $\mathrm{~J} 6 / 2 / 45 / 34$ & BF & BT-L \\
10. & $\mathrm{~J} 6 / 2 / 90 / 34$ & BF/FI & n.a. \\
11. & $\mathrm{~J} 6 / 2 / 45 / 25$ & FI & NT \\
12. & $\mathrm{~J} 6 / 2 / 90 / 25$ & BF & BT \\
13. & $\mathrm{~J} 6 / 3 / 45 / 25$ & FP & NT \\
14. & $\mathrm{~J} 6 / 3 / 90 / 25$ & FP & NT \\
15. & $\mathrm{~J} 6 / 4 / 45 / 34$ & FP & NT \\
16. & $\mathrm{~J} 6 / 4 / 70 / 34$ & FI & FP \\
17. & $\mathrm{~J} 6 / 4 / 70 / 25$ & $\mathrm{~J} 6 / 5 / 60 / 34$ &
\end{tabular}

Tests: BF-bolt failure by shear; FI—tearing from bolt hole to the edge of connected leg; FP-tearing from bolt hole to the edge of connected leg and propagation towards outstanding leg. FE modelling: NT-net section tearing; BT—block tearing; BT-L—mixed mode of failure (limited block tearing). 


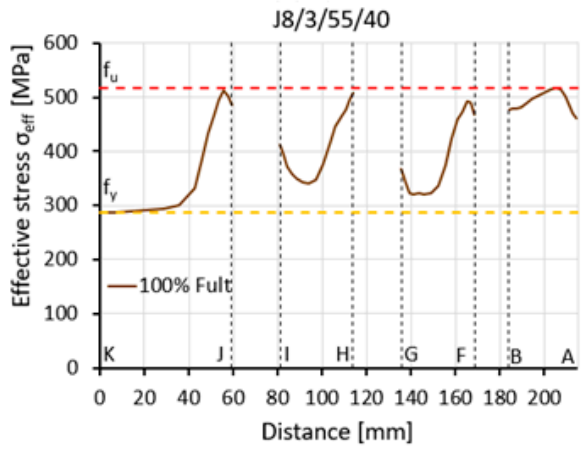

$\mathrm{J} 6 / 4 / 70 / 34$

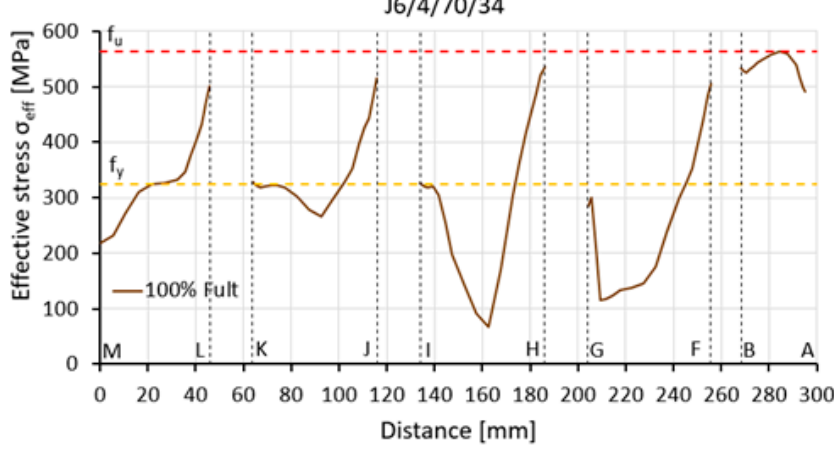

$\mathrm{J} 6 / 3 / 45 / 25$

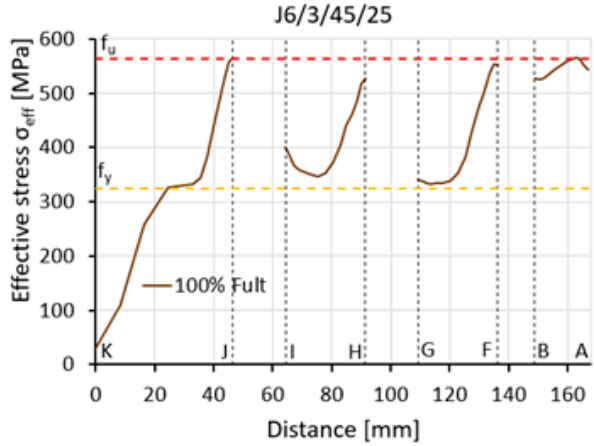

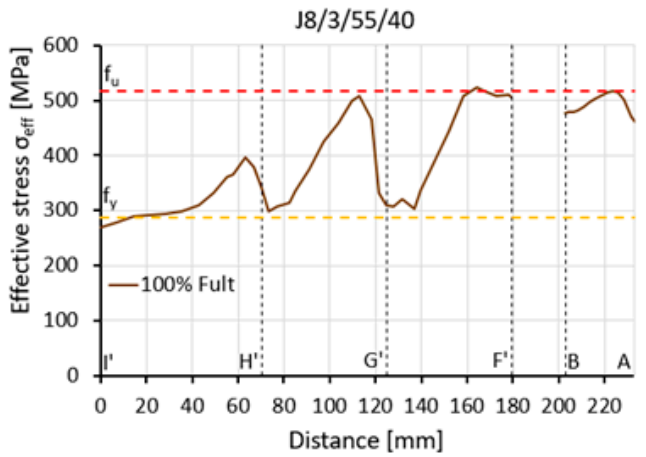

(a)

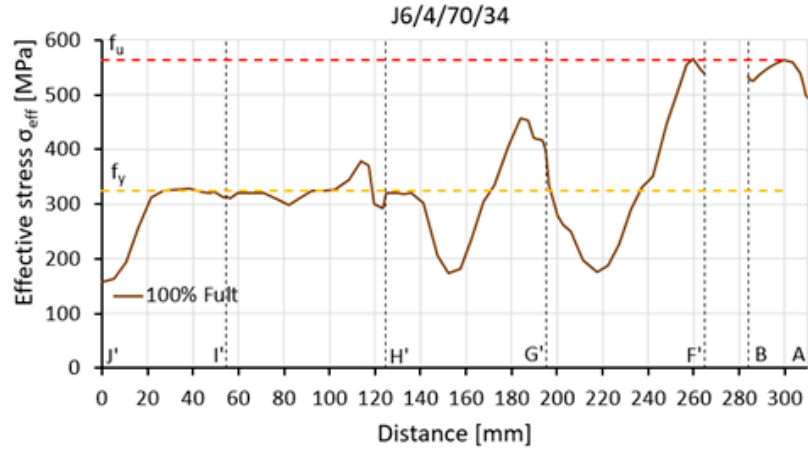

(b)

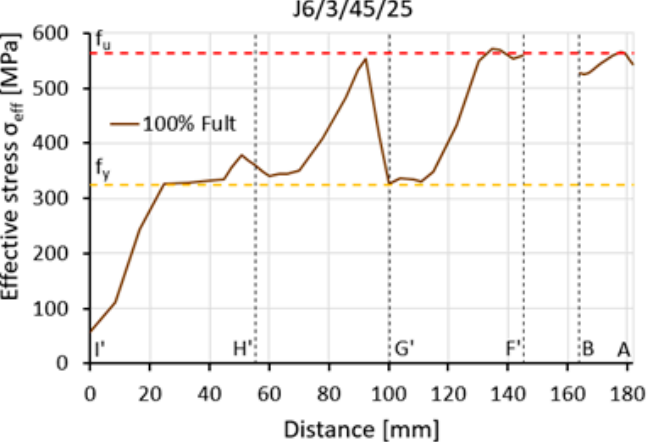

(c)

Figure 15. Effective stress distribution in block tearing sections for: (a) block tearing, (b) net section tearing, (c) limited block tearing (left diagrams for net cross section $\mathrm{A}_{\mathrm{nv}}$, right diagrams for gross cross section $\mathrm{A}_{\mathrm{gv}}$ ).

There was a very small correlation between the form of fracture observed during the tests and the failure mode determined by the effective stress distribution from the FEA. In addition, effective stress distributions along the net cross-section $\mathrm{A}_{\text {net }}$ (lines A-E) did not explicitly define the failure mode. However, they were helpful in assessing the conditions in which net section tearing occurred, as shown in Figure 16. The specimens in which net section tearing was predicted by observing the effective stress distribution were characterised by full utilisation of the ultimate resistance of the connected leg and partial utilisation of the ultimate resistance of the outstanding leg (clearly greater than the plastic load capacity). This resulted in high values of the efficiency factor of the net cross section $\mathrm{U}_{\text {eff }}=0.80-0.91$. In the specimens where block tearing or limited block tearing affected the failure mode, full utilisation of the ultimate resistance was reached only in section A-B of the connected leg.

As shown in Figure 17, it was also observed that the failure mode and efficiency factor of the net cross section $U_{\text {eff }}$ were dependent on the relative length of the bolted connections $\mathrm{L}_{\mathrm{j}} / \mathrm{d}_{0}$ (where $\mathrm{L}_{\mathrm{j}}$ is the distance between the centres of the end fasteners in a joint, measured in the direction of force transfer, and $\mathrm{d}_{0}$ is the diameter of the bolt hole). 


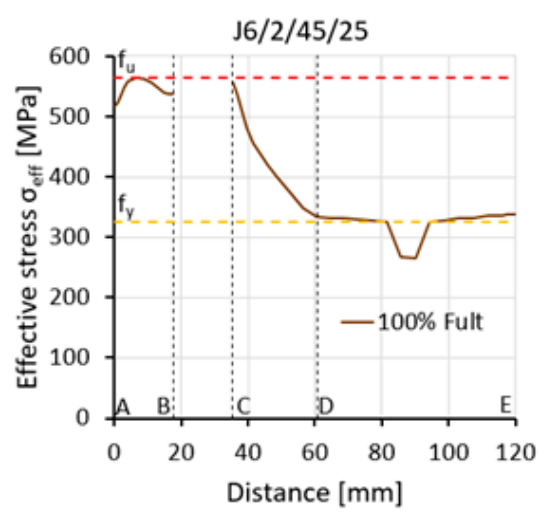

(a)

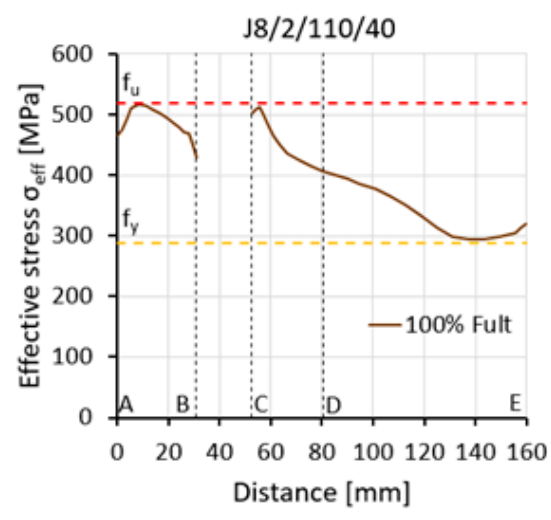

(b)

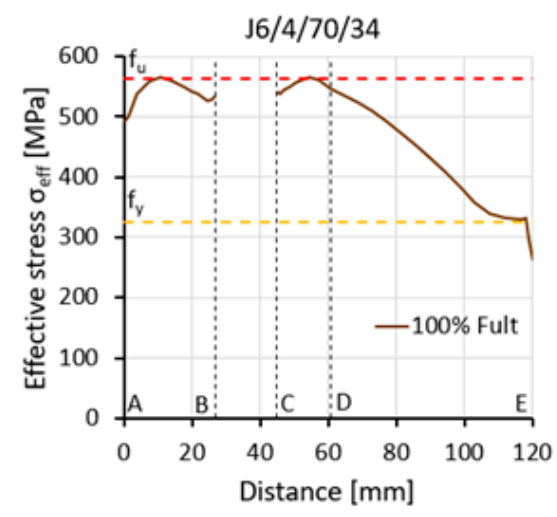

(c)

Figure 16. Effective stress distribution in net cross section $A_{\text {net }}$ (line $\left.A-D\right)$ for elements with various failure modes: (a) specimen J6/2/45/25 (limited block tearing); (b) specimen J8/2/110/40 (block tearing); (c) specimen J6/4/70/34 (net section tearing).

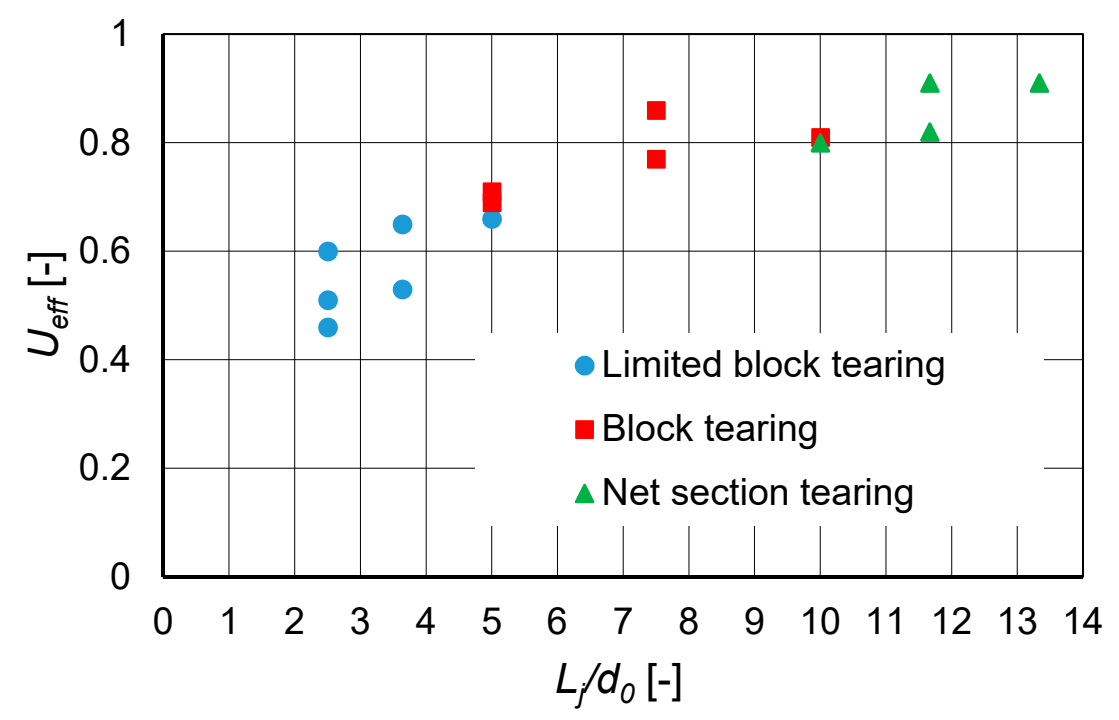

Figure 17. Dependence of efficiency factor $U_{\text {eff }}$ and failure mode on relative length of bolted connections $\mathrm{L}_{\mathrm{j}} / \mathrm{d}_{0}$.

The obtained results suggest that reaching the ultimate resistance of the angle based on net section tearing was possible only in the case of longer joints $\left(\mathrm{L}_{\mathrm{j}} / \mathrm{d}_{0} \geq 10\right)$. For shorter connections, the resistance decreased and the angle was subject to block tearing failure. These observations agree with results obtained by other researchers $[11,16,17]$, but the correlation between relative length of bolted connections $L_{j} / d_{0}$ and the observed mechanism of block tearing is a new finding. For joints characterised by proportion $5 \leq \mathrm{L}_{\mathrm{j}} / \mathrm{d}_{0} \leq 10$, the shear area could yield along the total length of the net or gross cross section. For very short joints $\left(\mathrm{L}_{\mathrm{j}} / \mathrm{d}_{0} \leq 5\right)$, the yielding of the shear area was limited along the end distance $\mathrm{e}_{1}$. The obtained ranges of $\mathrm{L}_{\mathrm{j}} / \mathrm{d}_{0}$ were relevant to the performed research, but this trend should be further explored in future work.

\section{Design Considerations}

European guidelines for tensioned angles connected by one leg are contained in EN 1993-1-8: Eurocode 3: Design of steel structures-Part 1-8: Design of joints [19]. According to this standard, a single angle in tension connected by a single row of bolts in one leg may be treated as concentrically loaded over an effective net section for which the design ultimate resistance should be determined as follows: 
- $\quad$ with one bolt:

$$
\mathrm{N}_{\mathrm{ult}, \mathrm{Rd}}=\frac{2.0 \cdot\left(\mathrm{e}_{2}-0.5 \mathrm{~d}_{0}\right) \cdot \mathrm{t} \cdot \mathrm{f}_{\mathrm{u}}}{\gamma_{\mathrm{M} 2}}
$$

- $\quad$ with two bolts:

$$
\mathrm{N}_{\mathrm{ult}, \mathrm{Rd}}=\frac{\beta_{2} \cdot \mathrm{A}_{\mathrm{net}} \cdot \mathrm{f}_{\mathrm{u}}}{\gamma_{\mathrm{M} 2}}
$$

- $\quad$ with three or more bolts:

$$
\mathrm{N}_{\mathrm{ult}, \mathrm{Rd}}=\frac{\beta_{3} \cdot \mathrm{A}_{\text {net }} \cdot \mathrm{f}_{\mathrm{u}}}{\gamma_{\mathrm{M} 2}}
$$

where $t$ is the thickness of the connected leg; $\beta_{2}$ and $\beta_{3}$ are reduction factors dependent on pitch $p_{1} ; A_{n e t}$ is the net area of the angle, and $\gamma_{\mathrm{M} 2}$ is a partial factor equal to 1.25.

Eurocode EN 1993-1-8 [19] also requires checking block tearing in lap bolted connections. It distinguishes two cases: for a symmetric bolt group subjected to concentric loading, the use of Equation (9), and for a bolt group subjected to eccentric loading, Equation (10):

$$
\begin{gathered}
\mathrm{V}_{\text {eff }, 1, R d}=\frac{A_{n t} \cdot f_{u}}{\gamma_{M 2}}+\frac{A_{n v} \cdot f_{y}}{\sqrt{3} \gamma_{M 0}} \\
V_{\text {eff }, 2, R d}=0.5 \cdot \frac{A_{n t} \cdot f_{u}}{\gamma_{M 2}}+\frac{A_{n v} \cdot f_{y}}{\sqrt{3} \gamma_{M 0}}
\end{gathered}
$$

where $A_{n t}$ is the net area subjected to tension, $A_{n v}$ is the net area subjected to shear, and $\gamma_{\mathrm{M} 0}$ is a partial factor equal to 1.0. For an angle connected by one leg with a single row of bolts, the stress on the tension area is uniform, and thus Equation (9) is recommended.

Final works on the new version of Eurocode prEN 1993-1-8: 2021 [36] are currently in progress. The proposals for changes include angles connected to one leg. In the new version, the method of calculating the tensile resistance for connections with one bolt does not change; however, for a larger number of fasteners, the tensile resistance should be determined from Equation (11) as the lower value of two: the ultimate tensile resistance of the net cross section and the block tearing resistance computed according to Equation $(12)[16,36]$ :

$$
\begin{gathered}
\mathrm{N}_{\mathrm{ult}, \mathrm{Rd}}=\min \left\{\frac{0.75 \cdot \mathrm{A}_{\mathrm{net}} \cdot \mathrm{f}_{\mathrm{u}}}{\gamma_{\mathrm{M} 2}} ; \mathrm{V}_{\mathrm{eff}, 1, \mathrm{Rd}}\right\} \\
\mathrm{V}_{\mathrm{eff}, 1, \mathrm{Rd}}=\left[\mathrm{A}_{\mathrm{nt}} \cdot \mathrm{f}_{\mathrm{u}}+\min \left\{\frac{\mathrm{A}_{\mathrm{gv}} \cdot \mathrm{f}_{\mathrm{y}}}{\sqrt{3}} ; \frac{\mathrm{A}_{\mathrm{nv}} \cdot \mathrm{f}_{\mathrm{u}}}{\sqrt{3}}\right\}\right] / \gamma_{\mathrm{M} 2}
\end{gathered}
$$

where $A_{g v}$ is the gross area subjected to shear; the rest of variables as in Equations (9) and (10).

Figure 18 and Table 6 present a comparison of the maximum tensile load obtained from the experimental test $\mathrm{F}_{\mathrm{ult}, \mathrm{Ex}}$ with the theoretical resistance $\mathrm{F}_{\text {teor }}$ calculated in accordance with two versions of Eurocode 3 part 1-8: the current version from 2005 [19] and the new draft from 2021 [36]. Using the current Eurocode theoretical resistance, $F_{\text {teor }}$ was computed as the minimum value of either the net cross section resistance from Equations (7) or (8), as appropriate according to the number of bolts used, or the block tearing resistance from Equation (9) because of uniform stress distribution along the $e_{2}$ distance. In accordance with the 2021 proposal [36], $\mathrm{F}_{\text {teor }}$ was computed using Equation (11). All partial factors were assumed to be 1.0. For each test element, except where only bolt failure was observed, values of the relative difference $\Delta_{\mathrm{F}}$ between $\mathrm{F}_{\text {teor }}$ and $\mathrm{F}_{\mathrm{ult}, \mathrm{Ex}}$ were calculated (vertical axis in Figure 18), according to Equation (5). The mean values of this parameter $\Delta_{\mathrm{F}, \mathrm{m}}$, as well as its standard deviation $\Delta_{\mathrm{F}, \mathrm{s}}$, minimum $\Delta_{\mathrm{F}, \min }$, and maximum $\Delta_{\mathrm{F}, \max }$ observed values are presented for each edition of the Eurocode in Table 6. If the theoretical resistance $F_{\text {teor }}$ was limited to Equations (7) or (8) in the case of the current Eurocode [19] or by the first term of 
Equation (11) in the case of the new Eurocode [36], the letter " $\mathrm{N}$ " in Table 6 is next to the $\Delta_{\mathrm{F}}$ value. If block tearing resistance limited $F_{\text {teor }}$, there is the indication " $\mathrm{V}$ ".

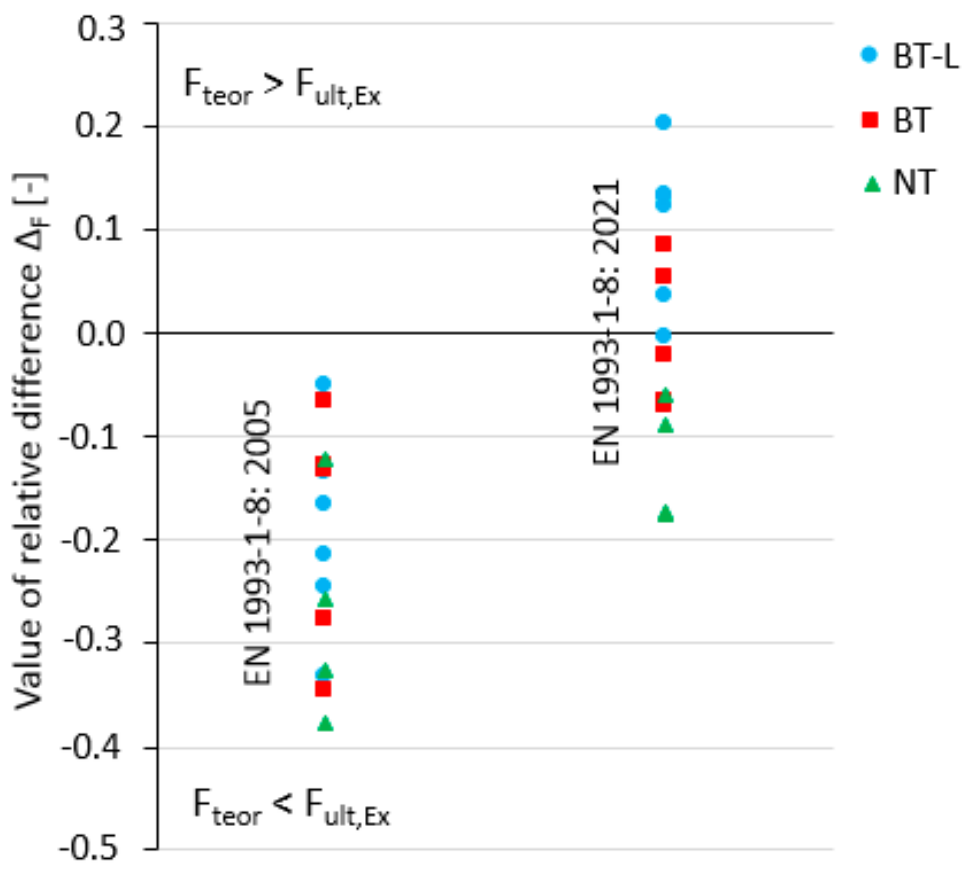

Figure 18. Comparison of relative difference $\Delta_{\mathrm{F}}$ between maximum tensile load obtained from experimental tests with theoretical resistance calculated according to Eurocode 3 (version from 2005 [19] and new proposal from 2021 [36]).

Table 6. Values of relative difference $\Delta_{\mathrm{F}}$ between theoretical resistance $\mathrm{F}_{\text {teor }}$ and experimental resistance $\mathrm{F}_{\mathrm{ult}, \mathrm{Ex}}$.

\begin{tabular}{|c|c|c|c|c|c|c|}
\hline \multirow[b]{2}{*}{ No. } & \multirow[b]{2}{*}{ Symbol } & \multirow[b]{2}{*}{$\begin{array}{l}\text { Failure Mode from } \\
\text { FE Model }\end{array}$} & \multicolumn{2}{|c|}{ EN 1993-1-8: 2005} & \multicolumn{2}{|c|}{ prEN 1993-1-8: 2021} \\
\hline & & & $\begin{array}{c}\text { Theoretical } \\
\text { Resistance Based on: }\end{array}$ & $\Delta_{\mathrm{F}}[-]$ & $\begin{array}{c}\text { Theoretical } \\
\text { Resistance Based on: }\end{array}$ & $\Delta_{\mathrm{F}}[-]$ \\
\hline 1. & $\mathrm{~J} 8 / 2 / 55 / 40$ & BT-L & $\mathrm{N}$ & -0.33 & $\mathrm{~V}$ & 0.0 \\
\hline 2. & $\mathrm{~J} 8 / 2 / 110 / 40$ & BT & $\mathrm{V}$ & -0.06 & $\mathrm{~N}$ & 0.05 \\
\hline 3. & $\mathrm{~J} 8 / 2 / 55 / 30$ & BT-L & $\mathrm{N}$ & -0.13 & $\mathrm{~V}$ & 0.12 \\
\hline 4. & $\mathrm{~J} 8 / 2 / 80 / 40$ & BT-L & $\mathrm{N}$ & -0.17 & $\mathrm{~V}$ & 0.04 \\
\hline 5. & $\mathrm{~J} 8 / 2 / 80 / 30$ & BT-L & $\mathrm{V}$ & -0.05 & $\mathrm{~V}$ & 0.13 \\
\hline 6. & $\mathrm{~J} 8 / 3 / 55 / 40$ & BT & $\mathrm{N}$ & -0.28 & $\mathrm{~N}$ & 0.09 \\
\hline 7. & $\mathrm{~J} 8 / 3 / 110 / 40$ & BT & $\mathrm{N}$ & -0.13 & $\mathrm{~N}$ & -0.07 \\
\hline 8. & $\mathrm{~J} 8 / 4 / 55 / 40$ & BT & $\mathrm{N}$ & -0.35 & $\mathrm{~N}$ & -0.02 \\
\hline 9. & $\mathrm{~J} 6 / 2 / 45 / 34$ & n.a. & - & - & - & - \\
\hline 10. & $\mathrm{~J} 6 / 2 / 90 / 34$ & BT & $\mathrm{N}$ & -0.13 & $\mathrm{~N}$ & -0.07 \\
\hline 11. & $\mathrm{~J} 6 / 2 / 45 / 25$ & BT-L & $\mathrm{N}$ & -0.21 & $\mathrm{~V}$ & 0.20 \\
\hline 12. & $\mathrm{~J} 6 / 2 / 90 / 25$ & n.a. & - & - & - & - \\
\hline 13. & $\mathrm{~J} 6 / 3 / 45 / 25$ & BT-L & $\mathrm{N}$ & -0.24 & $\mathrm{~N}$ & 0.13 \\
\hline 14. & $\mathrm{~J} 6 / 3 / 90 / 25$ & NT & $\mathrm{N}$ & -0.12 & $\mathrm{~N}$ & -0.06 \\
\hline 15. & $\mathrm{~J} 6 / 4 / 45 / 34$ & BT & $\mathrm{N}$ & -0.42 & $\mathrm{~N}$ & -0.13 \\
\hline 16. & $\mathrm{~J} 6 / 4 / 70 / 34$ & NT & $\mathrm{N}$ & -0.32 & $\mathrm{~N}$ & -0.17 \\
\hline 17. & $\mathrm{~J} 6 / 4 / 70 / 25$ & NT & $\mathrm{N}$ & -0.26 & $\mathrm{~N}$ & -0.09 \\
\hline \multirow[t]{5}{*}{18.} & $\mathrm{~J} 6 / 5 / 60 / 34$ & NT & $\mathrm{N}$ & -0.38 & $\mathrm{~N}$ & -0.17 \\
\hline & & & $\Delta_{\mathrm{F}, \mathrm{m}}$ & -0.22 & & 0.00 \\
\hline & & & $\Delta_{\mathrm{F}, \mathrm{S}}$ & 0.11 & & 0.12 \\
\hline & & & $\Delta_{\mathrm{F}, \min }$ & -0.42 & & -0.17 \\
\hline & & & $\Delta_{\mathrm{F}, \max }$ & -0.05 & & 0.20 \\
\hline
\end{tabular}


The current version of Eurocode 3 [19] estimates the theoretical resistance on a more conservative level. The mean value of the relative difference $\Delta_{\mathrm{F}}$ between the theoretical resistance $\mathrm{F}_{\text {teor }}$ and experimental resistance $\mathrm{F}_{\mathrm{ult} \text {,Ex }}$ was on the level of -0.22 . For 13 of the angle elements, the theoretical resistance was determined by net section tearing.

The performance of prEN 1993-1-8 [36] was characterised by a more favourable mean value $\Delta_{\mathrm{F}}$ parameter equal to 0.0 , based on the analyses performed in this study. However, an analysis of Figure 18 shows that, for individual strength functions, compatibility was not so high. For angles where net section tearing occurred, the 2021 draft theoretical resistance calculation underestimated the experimental results. For elements where typical block tearing occurred, the draft theoretical resistance gave very good estimates; the mean value of $\Delta_{\mathrm{F}}$ was equal to -0.02 . However, some angles were destroyed by a failure mode similar to block tearing, but characterised by not fully yielded end distance $e_{1}$ (in this paper classified as subject to limited block tearing failure (BT-L)). In this case, the draft standard theoretical resistance overestimated the experimental results in the range of $0.0-0.20$. This failure mode appeared in short connections $\left(\mathrm{L}_{\mathrm{j}} / \mathrm{d}_{0} \leq 5\right)$, and the line along which the rupture/yielding occurred was not consistent with typical block tearing, as shown in Figure 13.

\section{Summary and Conclusions}

The failure modes and the tension resistance of angle members connected by one leg with a single row of bolts were investigated experimentally and by means of FEA. Experimental tests indicated a significant influence of the total length of the connection and the edge distance $e_{2}$ on the tensile resistance; however, the obtained results did not allow for the explicit determination of the form of failure (block tearing or net section tearing). Hence, accurate, nonlinear FE models were developed to investigate failure modes. The GTN porous material model was used to analyse the connections through the full scope of the work, from the unloaded state to its rupture.

The main conclusions obtained from the research are as follows:

- The GTN material model prediction showed very high agreement with the results of the experimental tests of the load capacity and global behaviour of the elements.

- The failure modes obtained from FE modelling where GTN material was used agreed to a high degree with the test results regarding to the form of initiation of plastic fracture and its further development.

- Numerical analyses showed three possible failure modes: net-section tearing, typical block tearing and limited block tearing (block tearing with an area not fully sheared).

- This research indicates that, in very short connections $\left(\mathrm{L}_{\mathrm{j}} / \mathrm{d}_{0} \leq 5.0\right)$, limited block tearing may determine joint resistance. In this case, full plasticisation does not occur along length $\mathrm{e}_{1}$.

- The obtained results of load capacity compared with design procedures given in proposed revisions of Eurocode 3 [36] indicated a satisfactory agreement.

- Nevertheless, analytical models of block tearing did not precisely reflect the actual shear failure path observed in numerical simulations, especially for very short connections where limited block tearing was observed.

Owing to the desire to increase the efficiency of the production of steel structures and to save material, increasingly shorter angle connections are being designed. It seems that limited block tearing (block tearing with an area not fully sheared) is worth further investigation.

Author Contributions: Conceptualization, E.B. and L.Ś.; methodology, E.B. and L.Ś.; software, E.B.; validation, E.B.; formal analysis, E.B. and L.S.; investigation, E.B. and L.S.; writing—original draft preparation, E.B.; writing-review and editing, L.S.; supervision, L.Ś. Both authors have read and agreed to the published version of the manuscript.

Funding: This research was supported by a Polish Ministry of Science and Higher Education grant to maintain the research potential. 
Institutional Review Board Statement: Not applicable.

Informed Consent Statement: Not applicable.

Data Availability Statement: Data is contained within the article.

Acknowledgments: Technical support: Structures Testing Laboratory in the Faculty of Civil and Environmental Engineering and Architecture in Rzeszow University of Technology.

Conflicts of Interest: The authors declare no conflict of interest.

\section{References}

1. Munse, W.H.; Chesson, E.C., Jr. Riveted and bolted joints: Net section design. J. Struct. Div. 1963, 89, 107-126. [CrossRef]

2. Kulak, G.L.; Wu, E.Y. Shear lag in bolted angle tension members. J. Struct. Eng. 1997, 123, 1144-1152. [CrossRef]

3. Munter, H.L.N.; Bouwman, L.P. Angles Connected by Bolts in One Leg, Comparison to French, Eurocode 3 and Dutch Formulae with the Results of French and Dutch Tests; Report: 681 21; Stevin Laboratory, Department of Civil Engineering, Delft University of Technology: Delft, The Netherlands, 1981.

4. Birkemoe, P.C.; Gilmor, M.I. Behavior of bearing critical double-angle beam connections. Eng. J. AISC 1978, 15, $109-115$.

5. Orbison, J.G.; Wagner, M.E.; Fritz, W.P. Tension plane behavior in single-row bolted connections subject to block shear. J. Constr. Steel Res. 1999, 49, 225-239. [CrossRef]

6. Epstein, H.I. An experimental study of block shear failure of angles in tension. Eng. J. AISC 1992, $29,75-84$.

7. Ke, K.; Xiong, Y.; Yam, M.C.; Lam, A.C.; Chung, K. Shear lag effect on ultimate tensile capacity of high strength steel angles. J. Constr. Steel Res. 2018, 145, 300-314. [CrossRef]

8. Jiang, B.; Yam, M.C.; Ke, K.; Lam, A.C.; Zhao, Q. Block shear failure of S275 and S690 steel angles with single-line bolted connections. J. Constr. Steel Res. 2020, 170, 106068. [CrossRef]

9. Dhanuskar, J.R.; Gupta, L.M. Experimental investigation of block shear failure in a single angle tension member. Int. J. Steel Struct. 2020, 20, 1636-1650. [CrossRef]

10. Epstein, H.; Chamarajanagar, R. Finite element studies for correlation with block shear tests. Comput. Struct. 1996, 61,967-974. [CrossRef]

11. Topkaya, C. A finite element parametric study on block shear failure of steel tension members. J. Constr. Steel Res. 2004, 60, 1615-1635. [CrossRef]

12. Helwe, M.B.; El Kalash, S.; Hantouche, E.G. Alternate block shear in beams: Experimental and FE fracture modeling. Eng. Struct. 2019, 186, 110-120. [CrossRef]

13. Wen, H.; Mahmoud, H. Simulation of block shear fracture in bolted connections. J. Constr. Steel Res. 2017, 134, 1-16. [CrossRef]

14. Ma, R.; Yu, L.; Zhang, H.; Tan, L.; Kueh, A.B.; Feng, J.; Cai, J. Experimental and numerical appraisal of steel joints integrated with single- and double-angles for transmission line towers. Thin-Walled Struct. 2021, 164, 107833. [CrossRef]

15. Sharda, A.; Manalo, A.; Ferdous, W.; Bai, Y.; Nicol, L.; Mohammed, A.; Benmokrane, B. Axial compression behavior of allcomposite modular wall system. Compos. Struct. 2021, 268, 113986. [CrossRef]

16. Može, P. Statistical evaluation of bearing resistance and related strength functions for bolted connections. J. Constr. Steel Res. 2020, 171, 106128. [CrossRef]

17. Može, P. Angles connected by one leg in tension. Ce/papers 2017, 1, 3771-3780. [CrossRef]

18. EN 1090-2 Execution of Steel Structures and Aluminium Structures-Part 2: Technical Requirements for Steel Structures; CEN: Brussels, Belgium, 2018.

19. EN 1993-1-8 Eurocode 3: Design of Steel Structures-Part 1-8: Design of Joints; CEN: Brussels, Belgium, 2005.

20. EN ISO 6892-1 Metallic Materials_Tensile Testing_Part 1: Method of Test at Room Temperature; CEN: Brussels, Belgium, 2019.

21. Kanvinde, A. Predicting fracture in civil engineering steel structures: State of the art. J. Struct. Eng. 2017, 143, 03116001. [CrossRef]

22. Francois, D.; Pineau, A.; Zaoui, A. Mechanical Behaviour of Materials. Volume II: Fracture Mechanics and Damage; Springer: Dordrecht, 2013.

23. Gurson, A.L. Continuum theory of ductile rupture by void nucleation and growth: Part I-Yield criteria and flow rules for porous ductile media. J. Eng. Mater. Technol. 1977, 99, 2-15. [CrossRef]

24. Feldmann, M.; Schaffrath, S. Application of damage theory to structures made from high-strength steels. Steel Constr. 2018, 11, 257-263. [CrossRef]

25. Feldmann, M.; Schaffrath, S. Assessing the net section resistance and ductility requirements of EN 1993-1-1 and EN 1993-1-12. Steel Constr. 2017, 10, 354-364. [CrossRef]

26. Kossakowski, P. Simulation of ductile fracture of S235JR steel using computational cells with microstructurally-based length scales. J. Theor. App. Mech. Pol. 2012, 50, 589-607.

27. Qian, X.D.; Choo, Y.S.; Liew, R.; Wardenier, J. Simulation of ductile fracture of circular hollow section joints using the Gurson model. J. Struct. Eng. 2005, 131, 768-780. [CrossRef]

28. EN 10025 Hot Rolled Products of Structural Steels; CEN: Brussels, Belgium, 2007.

29. Kossakowski, P.; Wciślik, W. Numerical simulation of material damage for structural steels S235JR and S355J2G3. Adv. Comput. Des. 2018, 3, 133-146. [CrossRef] 
30. Kossakowski, P. Analysis of the void volume fraction for S235JR steel at failure for low initial stress triaxiality. Arch. Civ. Eng. 2018, 64, 101-115. [CrossRef]

31. Bernatowska, E. Numerical simulations of ductile fracture in steel angle tension members connected with bolts. Civ. Environ. Eng. Rep. 2020, 30, 32-54. [CrossRef]

32. Abaqus, Version 6.16; Dassault Systemes: Vélizy-Villacoublay, France, 2016.

33. Kim, T.S.; Kuwamura, H. Finite element modeling of bolted connections in thin-walled stainless steel plates under static shear. Thin Walled Struct. 2007, 45, 407-421. [CrossRef]

34. Salih, E.; Gardner, L.; Nethercot, D. Numerical investigation of net section failure in stainless steel bolted connections. J. Constr. Steel Res. 2010, 66, 1455-1466. [CrossRef]

35. Kim, J.; Yoon, J.-C.; Kang, B.-S. Finite element analysis and modeling of structure with bolted joints. Appl. Math. Model. 2007, 31, 895-911. [CrossRef]

36. prEN 1993-1-8:2021: Eurocode 3-Design of Steel Structures_Part 1-8: Design of Joints; CEN/TC250: Brussels, Belgium, 2021. 